\title{
REVISTA DE ARQUITECTURA
}
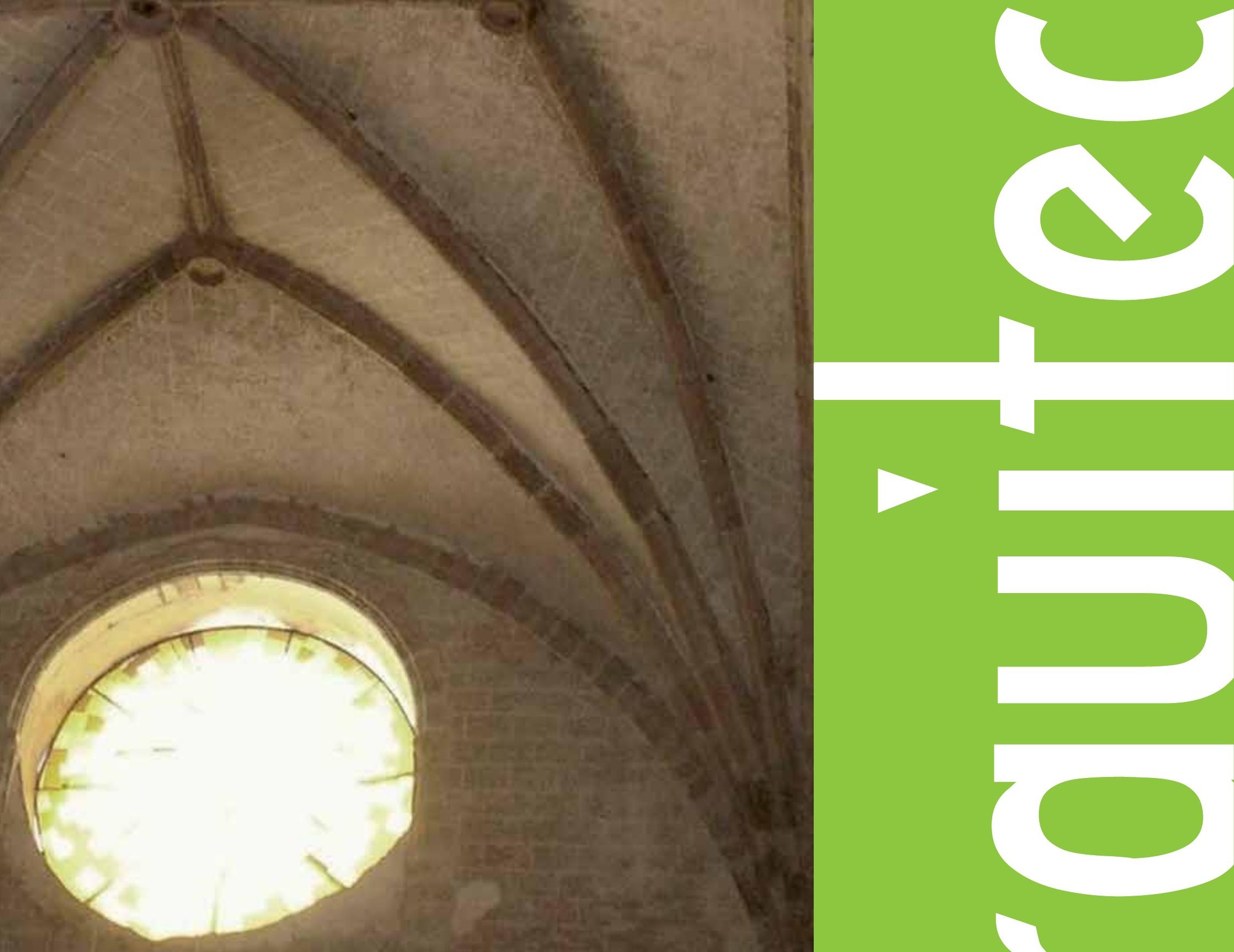

車 
La Revista de Arquitectura es una publicación seriada dirigida a la comunidad académica y profesional de las áreas afines a la disciplina (Arquitectura y Urbanismo), en donde se presentan resultados originales e inéditos de investigación. El primer número se publicó en 1999 y continúa con una periodicidad anual; es editada por la Facultad de Arquitectura de la Universidad Católica de Colombia. La revista se estructura en tres secciones correspondientes a las líneas de investigación aprobadas por la institución, a saber:

CULTURA Y ESPACIO URBANO. En esta sección se publican los artículos que se refieren a fenómenos sociales en relación con el espacio y el territorio urbano.

PROYECTO ARQUITECTÓNICO Y URBANO. Esta sección presenta artículos sobre el concepto de proyecto, entendido como elemento que define y orienta las condiciones proyectuales que devienen en los hechos arquitectónicos o urbanos, y la forma como estos se convierten en un proceso de investigación y de producción nuevo de conocimiento. También se presentan proyectos que sean resultados de investigación, que se validan a través de la ejecución y transformación en obra construida del proceso investigativo.

TECNOLOgíA, MEDIOAMBIENTE Y SOSTENIBILIDAD. En esta sección se presentan artículos acerca de sistemas estructurales, materiales y procesos constructivos, medioambiente y gestión, relacionados con el entorno social, cultural y ecológico.

\section{(A) Imagen base de la portada:}

Bóvedas del coro y de la nave del templo de Oaxtepec.

Foto: Natalia García, 2011

La Revista de Arquitectura recibe de manera permanente artículos, por lo cual no existen fechas de apertura y cierre de convocatorias.

El idioma principal es el español y como opcionales están definidos el inglés y el portugués; los textos pueden ser escritos y presentados en cualquiera de estos.

A El editor y los autores son responsables de los artículos aquí publicados.

Los autores son los responsables del material gráfico publicado.

Se autoriza la reproducción total o parcial de los artículos, siempre y cuando se haga la solicitud formal y se citen la fuente y el autor.
A Universidad Católica de Colombia (2012, enero-diciembre). Revista de Arquitectura, 14. 1-128. ISSN: 1657-0308

Especificaciones:

Formato: $\quad 34 \times 24 \mathrm{~cm}$

Papel: $\quad$ Mate $115 \mathrm{~g}$

Tintas: Negro y policromía

Periodicidad: Anual 


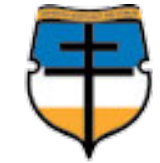

UNIVERSIDAD CATÓLICA de Colombia

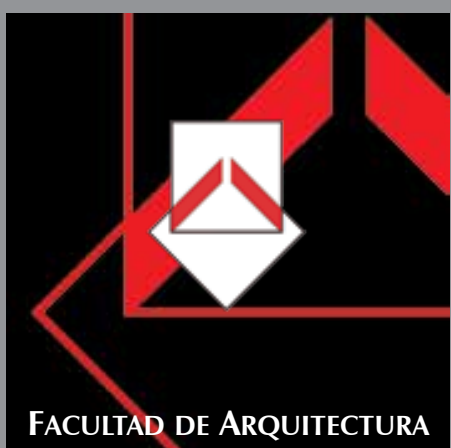

FACULTA
UNIVERSIDAD CATÓLICA

\section{DE COLOMBIA}

PRESIDENTE

Édgar Gómez Betancourt

VICEPRESIDENTE - RECTOR

Francisco José Gómez Ortiz

VICERRECTOR JURÍDICO Y DEL MEDIO

UNIVERSITARIO

Edwin de Jesús Horta Vásquez

VICERRECTOR ADMINISTRATIVO

Édgar Gómez Ortiz

DECANA ACADÉMICA

Irene Rodríguez Castillo

DIRECTORA DE INVESTIGACIONES

María Eugenia Guerrero Useda

DIRECTORA DE EDICIONES

Stella Valbuena García

\section{FACULTAD DE ARQUITECTURA}

DECANO

Werner Gómez Benítez

DIRECTOR DE DOCENCIA

Jorge Gutiérrez Martínez

DIRECTOR DE EXTENSIÓN

Carlos Beltrán Peinado

DIRECTOR DE INVESTIGACIÓN

Juan Carlos Pérgolis

DIRECTOR DE GESTIÓN DE CALIDAD

Augusto Forero La Rotta

COMITÉ ASESOR EXTERNO

FACULTAD DE ARQUITECTURA:

Alberto Miani Uribe

Octavio Moreno

Felipe Bernal Henao

Lorenzo Castro

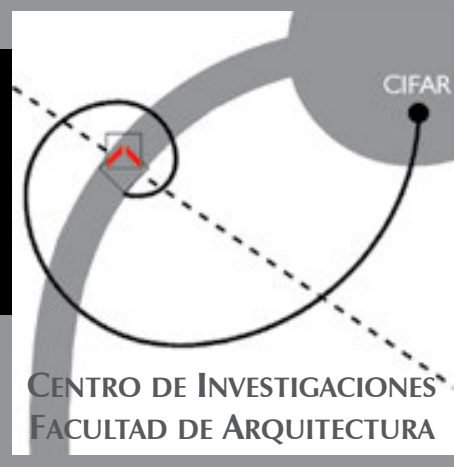

REVISTA ARBITRADA E INDEXADA

Publindex. Índice Bibliográfico Nacional IBN -

Redalyc. Red de Revistas Cientíícas de América Latina

y el Caribe, España y Portugal. Sistema de Información

Clase. Base de datos bibliográfica de revistas de

ciencias sociales y humanidades. Universidad

Autónoma México.

Ebsco. EBSCOhost Research Databases. Estados

Unidos.

Latindex. Sistema Regional de Información en Línea

para Revistas Científicas de América Latina, el Caribe,

España y Portugal (Directorio). México.

Dialnet. Fundación Dialnet - Biblioteca de la

Universidad de La Rioja. España.

Actualidad Iberoamericana. (Índice de Revistas) Centro

献

Arla. Asociación de revistas latinoamericanas de

arquitectura.

SUSCRIPCIONES, ADQUISICIONES Y

COMENTARIOS

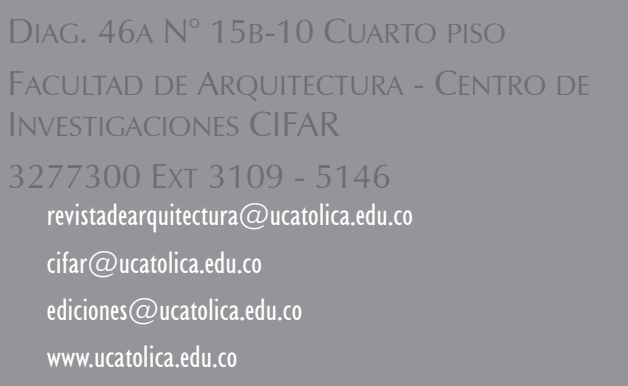

IMPRESIÓN:

ESCALA Taller Litográfico

Calle $30 \mathrm{~N}^{\circ}$ 17-52 - (057 I) 2320482

Diciembre de 2012

\section{REVISTA DE ARQUITECTURA}

DIRECTOR

Werner Gómez Benítez

EDITOR

César Andrés Eligio Triana

CONSEJO EDITORIAL

Werner Gómez Benítez

Jorge Gutiérrez Martínez

César Andrés Eligio Triana

Carlos Beltrán Peinado

Hernando Verdugo Reyes

IMAGEN \& DISEÑO

DISEÑO Y MONTAJE

Juanita Isaza - juanaisaza@gmail.com

TRADUCTOR TÉCNICO

Carlos Álvarez de la Roche

CORRECTORA DE ESTILO

María José Díaz Granados M.

PÁGINA WEB

Óscar Mauricio Pérez

DISTRIBUCIÓN Y CANJES

Claudia Álvarez Duquino
COMITÉ EDITORIAL

(A) Sonia Berjman, Ph.D.

ICOMOS, Buenos Aires, Argentina

Beatriz García Moreno, Ph.D.

Universidad Nacional de Colombia. Bogotá, Colombia

Juan Carlos Pérgolis, Msc.

Universidad Católica de Colombia. Bogotá, Colombia

René Julio Castillo, Msc. Ph.D. (Estudios)

Universidad del Rosario. Bogotá, Colombia

A Hugo Modragón López, Ph.D. Pontificia Universidad Católica de Chile. Santiago, Chile

Juan Pablo Duque Cañas, Ph.D. Universidad Nacional de Colombia. Bogotá, Colombia

Germán Darío Correal Pachón, Msc. Universidad Católica de Colombia. Bogotá, Colombia

(A) Luis Gabriel Gómez Azpeitia, Ph.D. Universidad de Colima. Colima, México

Luis Carlos Herrera Sosa, Ph.D. Universidad Autónoma de Ciudad Juárez, México

COMITÉ CIENTíFICO

Jorge Grané del Castillo, Msc. Universidad de Costa Rica. San José, Costa Rica

Javier Peinado Pontón, Msc. Pontificia Universidad Javeriana. Bogotá, Colombia

Jorge Alberto Villamizar Hernández Universidad Santo Tomás. Bucaramanga, Colombia

Augusto Forero La Rotta, Msc. Universidad Católica de Colombia. Bogotá, Colombia

Luis Álvaro Flórez Millán, Msc. Universidad Católica de Colombia. Bogotá, Colombia

Elvia Isabel Casas Matiz, Msc.

Universidad Católica de Colombia. Bogotá, Colombia 


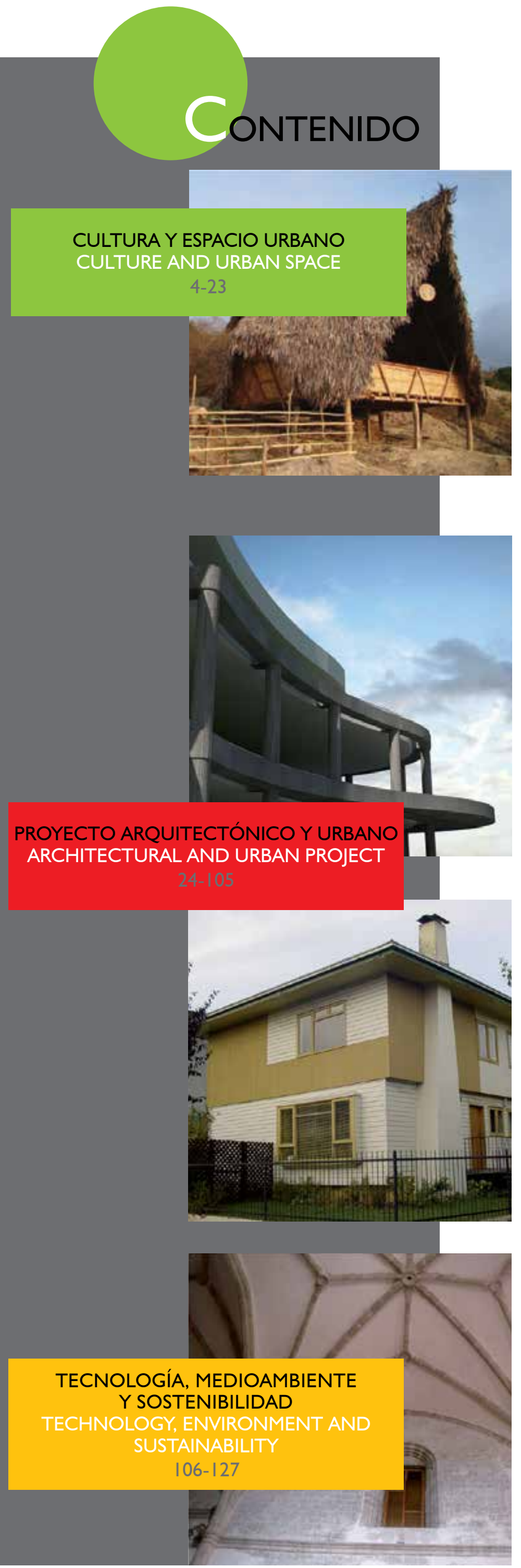

ARQUITECTURA PARTICIPATIVA:

LAS FORMAS DE LO ESENCIAL

WILLIAM GARCÍA R.

PÁG. 4

LA CIUDAD MODERNA,

LITERALMENTE HABLANDO

O CÓMO LEER LO QUE DICEN LOS ESCRITORES DE

FICCIÓN SOBRE LA ARQUITECTURA Y EL URBANISMO

MAURICIO MUÑOZ

UNA VENTANA PARA VER LA CIUDAD:

EL PARK WAY ( I 944-2000)

José ORLANDO JAIMES NIETO

PÁG. 20

CARÁCTER, CARÁCTER PÚBLICO, CARACTERES NACIONALES.

VARIACIONES, PERSISTENCIAS E INTERPRETACIONES EN TORNO A LA EDILICIA PÚBLICA

Daniela Alejandra CATtANeO

UN ACERCAMIENTO AL ESPACIO ARQUITECTÓNICO

FRANCISCO JAVIER FUENTES FARIAS

PÁG. 36

\section{PROPUESTA DE DISEÑO DE UN TEATRO} PARA I500 ESPECTADORES

UNA MIRADA DESDE LOS ORÍGENES DE ESTA TIPOLOGÍA ARQUITECTÓNICA

NORA ALVARIÑO TAPIA

ERNESTO FELIPE SÁNCHEZ

GRANDES IDEAS DEL MUNDO:

\section{UNA REALIDAD CONCRETA}

TENSIONES EN LA VIVIENDA UNIFAMILIAR MODERNA, OSORNO, CHILE

Hugo EduARdo Weibel FERNÁNDEZ

ESTUDIO Y GESTIÓN DE ESTÁNDARES MÍNIMOS DE FLEXIBILIDAD EN LA VIVIENDA SOCIAL EN BOGOTÁ

ROLANDO ARTURO CUBILLOS GONZÁLEZ

ESTRATEGIA DIDÁCTICA PARA EL APRENDIZAJE DE LA HISTORIA Y LA TEORÍA DE

LA ARQUITECTURA

MAYERLY ROSA VILLAR LOZANO

\section{LO MISMO MUY DE OTRA MANERA}

SOBRE LA RELACIÓN ENTRE PROYECTO Y ANÁLISIS EN EL APRENDIZAJE DE LA COMPOSICIÓN ARQUITECTÓNICA

RAFAEL FRANCESCONI LATORRE

\section{TIPO, ANÁLISIS Y PROYECTO}

GERMÁN DARÍO RODRÍGUEZ BOTERO

TRAZO DE LAS BÓVEDAS DE NERVADURAS MEXICANAS DEL SIGLO XVI

NATALIA GARCÍA GÓMEZ

CONCEPTUALIZACIÓN DE UN MODELO DE INTERVENCIÓN URBANA SOSTENIBLE

ECOBARRIOS EN EL CONTEXTO LATINOAMERICANO DE RECIENTE INDUSTRIALIZACIÓN

ADRIANA PATRICIA LÓPEZ VALENCIA

OSWALDO LÓPEZ BERNAL 


\section{EDITORIAL}

\section{¿HACIA DÓNDE VA LA PRODUCCIÓN ESCRITA EN ARQUITECTURA?}

La producción escrita en el campo de la arquitectura tiene diversas facetas, pero poco a poco ha migrado hacia la producción científica; al respecto, es de resaltar el creciente número de revistas que se orientan hacia la divulgación de resultados de investigación. Particularmente en nuestro país, años atrás solo eran unas pocas las encargadas de esta labor, entre esas la Revista de Arquitectura. Hoy en día el número crece, ya se pueden contar en la plataforma Publindex (2012) diez publicaciones que comparten este interés (no todas indexadas); a este número se le pueden agregar algunas que abordan otras áreas del conocimiento y que hacen parte del fundamento epistemológico de la disciplina, como el planeamiento urbano y regional, la historia o algunas que presentan temas de arquitectura y ciudad vistos desde el arte.

Es cierto que esta tendencia creciente es un buen indicador para el área de la arquitectura y el urbanismo, aunque si se compara con otras áreas de conocimiento la producción científica escrita todavía evidencia un bajo desarrollo. La cultura del libro en el campo arquitectónico se mantiene como una fortaleza, muchas investigaciones se presentan más en este formato que como artículos; en nuestro contexto es fácil reconocer algunos autores vinculados con la producción de libros, pero al mirarlos en relación con la producción de artículos sus nombres desaparecen.

Tampoco se puede desconocer el papel que han jugado las publicaciones "no científicas" en la documentación de nuestro acervo arquitectónico y urbano como lo fue Proa, en su momento, o la Revista Escala, la cual cumple cincuenta años en esta labor y cada día muestra más el contexto latinoamericano. A nivel internacional muchas revistas de este tipo fueron guiadas por maestros de la arquitectura y se convirtieron en espacio de discusión de nuevos postulados y teorías que guiaron el horizonte de la disciplina. Este "otro" tipo de publicaciones es complemento obligado de las publicaciones científicas, ante las cuales muchas de estas se muestran como el inicio de un cambio de cultura en la manera de ver y pensar la arquitectura y, como todo cambio cultural, necesita de tiempo y de compromiso.

La Revista de Arquitectura, inscrita en el marco del Proyecto Educativo Institucional (PEI) y del Proyecto Educativo del Programa de Arquitectura (PEP), es un espacio de discusión de los compromisos y las miradas propias del programa; la visión del proyecto como unidad totalizadora, el diseño concurrente como síntesis de diferentes campos de conocimiento, la pedagogía y la didáctica como medios de transformación de las personas, entre otros, son temas que se ven reflejados en cada edición de la publicación.

A partir de las convocatorias para postulación de artículos, y en los últimos volúmenes publicados, se pueden detectar tendencias de investigación en las cuales el tema urbano y el proyecto son dominantes, aunque el primero ha disminuido su participación.

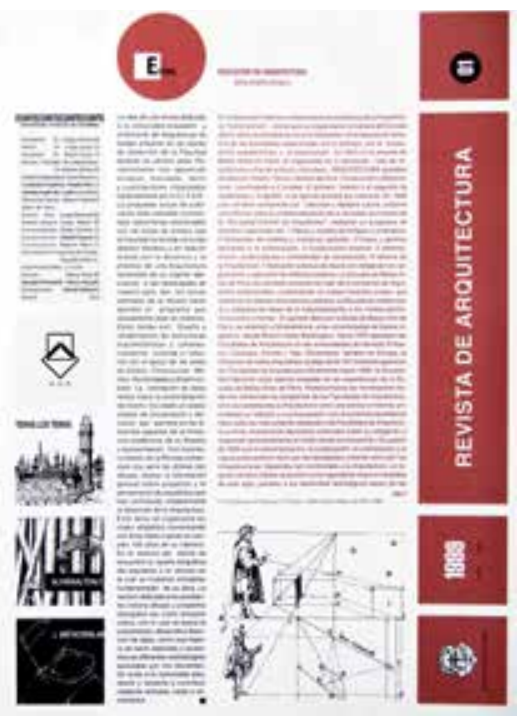

४ Figura 1

Primer número de la Revista de Arquitectura

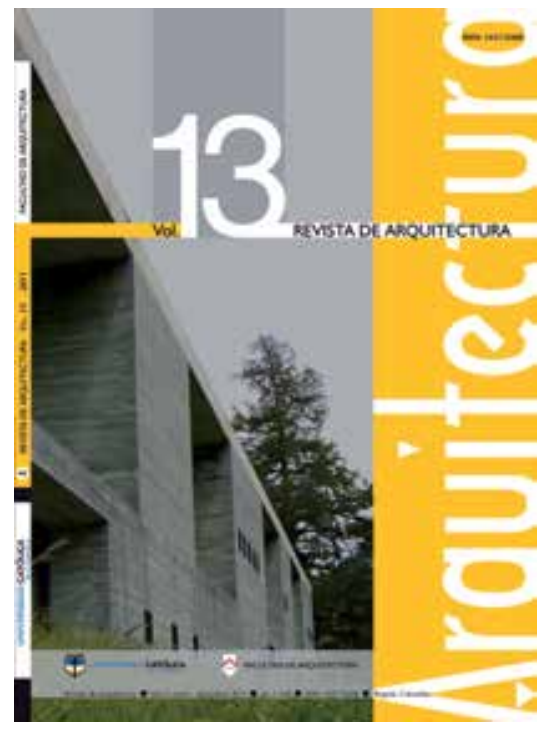

( Figura 2

Volumen 13 de la Revista de Arquitectura

La sección de "Cultura y espacio urbano" ha sido orientada por las miradas sobre temas como imaginarios y representaciones sociales e historia urbana. "Proyecto arquitectónico y urbano" ha ocupado mayor protagonismo y se pueden destacar diferentes frentes de acción, como la historia y la crítica arquitectónica, la construcción del proyecto como problema formal, espacial y social, así como la pedagogía y la didáctica en la arquitectura.

La sección "Tecnología, medioambiente y sostenibilidad" es aquella en la cual la participación es más escasa, sus temas recurrentes son los sistemas informáticos y estructurales, junto con los materiales. La baja producción en esta sección es extraña, ya que los tres componentes que la conforman son los más tratados en los discursos actuales —no solo de la arquitectura-, son realidades del mundo contemporáneo sobre las cuales la academia debería trabajar con mayor fuerza. Los cambios en estos temas son vertiginosos y las universidades y la industria tienen una gran responsabilidad al respecto.

La producción escrita se debe fortalecer, el trabajo en comunidades académicas es indispensable para continuar con este cambio de cultura; los autores, los evaluadores y las instituciones deben ser conscientes de la calidad y del rol que juegan en el avance del conocimiento, se debe buscar el acercamiento con la empresa y el sector productivo y, sobre todo, trascender las fronteras para garantizar la divulgación y la apropiación del conocimiento. 


\section{TRAZO DE LAS BÓVEDAS DE NERVADURAS MEXICANAS DEL SIGLO XVI}

\section{NATALIA GARCÍA GÓMEZ \\ Universidad Autónoma del Estado de Morelos, Facultad de Arquitectura. México \\ Programa para el Mejoramiento del Profesorado (Promep)}

Arquitecta, Universidad Veracruzana, Xalapa, Veracruz, México.

Maestra en Ingeniería de Estructuras, Universidad Veracruzana, Veracruz, México.

García Gómez, N. (20I2) Trazo de las bóvedas de nervaduras mexicanas del siglo XVI. Revista de Arquitectura, 14 106-II5.

Doctora en Ingeniería de Estructuras, Universidad Nacional

Autónoma de México (UNAM), México, D. F.

Candidato en el Sistema Nacional de Investigadores del Consejo Nacional de Ciencia y Tecnología (Conacyt), periodo 20I I-20I3. Publicaciones: On Structural bases for building the Mexican convent churches from the sixteenth century. International Journal of Architectural Heritage, 3: 24-5I (2009) ISSN: I558-3058. natgargz@gmail.com

\section{RESUMEN}

En este trabajo se estudiaron los templos conventuales mexicanos construidos en el siglo XVI, techados totalmente con bóvedas de nervaduras. El objetivo consistió en identificar sus características geométricas y el origen del trazo de los elementos estructurales que conforman estos templos. Para ello se eligieron cuatro iglesias conventuales en función de la relevancia de sus características geométricas y constructivas para su comportamiento estructural, y por su periodo de construcción. A partir de tratados de construcción de la época se identificó la geometría y el trazo de las bóvedas y algunos aspectos básicos del dimensionamiento de sus contrafuertes. Esto ha servido a fin de establecer una base para el estudio de los lineamientos seguidos por sus constructores en la búsqueda de garantizar la estabilidad de estas edificaciones, así como para estudios posteriores de su comportamiento estructural.

PALABRAS CLAVE: arquitectura religiosa, bóvedas de crucería, conventos mexicanos, templos conventuales, tratados de construcción.

TRACING OF RIBBED VAULTS OF THE I6TH CENTURY IN MEXICO

\section{ABSTRACT}

In this paper were studied the Mexican conventual temples built in the XVI century, roofed totally with ribbed vaults. The objective consisted on identifying its geometric characteristics and the origin of the line of the structural elements that conforms these temples. For this were chosen four conventual churches in function of the relevance of their geometric and constructive characteristics for their structural behavior, and for their period of construction. Starting from treaties of construction of the time it was identified the geometry and the line of the vaults and some basic aspects of the dimensioning of their buttresses. This has served in order to establish a base for the study of the limits continued by their manufacturers in the search of guaranteeing the stability of these constructions, as well as it stops later studies of their structural behavior.

KEY WORDS: Religious architecture, ribbed vaults, Mexican convents, monastic churches, architectural treatises. 


\section{INTRODUCCIÓN}

Este escrito forma parte del proyecto de investigación financiado por el Programa para el Mejoramiento del Profesorado (Promep) de la Secretaría de Educación Pública (SEP), en la convocatoria 2010, con el título "Comportamiento estructural de los edificios coloniales abovedados en México". El trabajo fue desarrollado en la Facultad de Arquitectura de la Universidad Autónoma del Estado de Morelos y tiene su antecedente en la línea de investigación de la autora, dirigida al estudio de la concepción de la estructura de los templos conventuales mexicanos del siglo XVI, a partir del análisis de las reglas contenidas en antiguos tratados de construcción y su relevancia en el comportamiento estructural de estos edificios (García y Meli, 2009).

La abundante obra de edificación realizada en México durante el siglo XVI por las órdenes mendicantes franciscana, dominica y agustina, ayudadas por la cuantiosa mano de obra indígena, calificada para emprender grandes obras de mampostería, es ahora para nosotros una muestra relevante de la práctica constructiva de esa época, y su estudio nos permite conocer con mayor profundidad las bases de su diseño. Los sistemas constructivos empleados en estos edificios fueron variados según las posibilidades del lugar, de las condiciones generales a las que debieron adaptarse los constructores europeos, y de las enseñanzas que recibieron de la práctica constructiva prehispánica. Los grandes conjuntos conventuales típicos, logrados por las tres órdenes mendicantes que llegaron a México, están conformados por el convento y el templo, que usualmente están en un atrio o espacio abierto de planta rectangular de grandes dimensiones, delimitado por una barda, en el que puede haber una capilla abierta al lado del templo y capillas posas en sus esquinas.

De los elementos arriba descritos, que conforman los conjuntos conventuales, en este trabajo son de interés los templos, cuyas características han sido definidas por Kubler (1983, p. 241), quien señala que el prototipo fue el de nave única sin crucero o nave rasa, de gruesos muros de mampostería y contrafuertes de gran volumen que soportan una bóveda de cañón corrido. Aunque este tipo de cubierta fue la más común, también se construyeron iglesias techadas totalmente con bóvedas de nervaduras, que si bien se edificaron en mucho menor número que las de cañón corrido, constituyen un sistema de cubierta relevante que ha sido poco estudiado y es motivo del presente trabajo. El propósito principal está dirigido al conocimiento del trazo de bóvedas de nervaduras, así como de las características y el origen del dimensionamiento de sus contrafuertes; el objetivo es indagar en el origen de su diseño y sentar las bases para la mejor comprensión de su trabajo estructural. Se partió de la revisión de tratados de construcción españoles y del estudio de su posible aplicación en las edificaciones religiosas mexicanas, con lo que fue posible identificar la geometría de las bóvedas nervadas y sus contrafuertes, y sentar las bases de su diseño conforme a las reglas propuestas en antiguos manuscritos de construcción.

\section{Metodología}

Para lograr el objetivo planteado en este trabajo se recurrió primero a una revisión de los antecedentes de las bóvedas de nervaduras en los países donde se originó este sistema de cubierta. Se estudiaron los aspectos más relevantes de su tradición constructiva, particularmente en España; de esta manera fue posible identificar diversos lineamientos para su trazo y edificación en tratados de construcción. Estos procedimientos fueron ensayados en algunos templos conventuales mexicanos cuyas características son representativas desde el punto de vista geométrico y por su posible influencia en el comportamiento de su estructura. Se hizo una revisión general de los templos mexicanos cubiertos totalmente con bóvedas nervadas que permanecen hasta nuestros días, y para el estudio detallado del trazo de las bóvedas se eligieron las iglesias conventuales ubicadas en Cholula, Tula, Acatzingo y Oaxtepec, de las que se contó con un levantamiento previo realizado por una empresa, mediante un equipo de escáner láser (figura 5). Estos templos se eligieron conforme a sus características geométricas y estructurales, asî como al periodo de su construcción. Los modelos se trabajaron en ambiente CAD para facilitar el estudio de cada nervadura y de la plementería. La geometría real de las bóvedas se comparó con la de los procedimientos descritos por dos tratadistas españoles que han sido estudiados por diversos autores contemporáneos de ese país. Primero se identificó el método usado para trazar los terceletes en planta y, posteriormente, para trazar la montea, se "volteó" cada una de las nervaduras a partir de la planta de la bóveda. Para estudiar los contrafuertes que sustentan estas cubiertas se aplicaron las reglas de tres tratadistas de la época y se compararon con las dimensiones reales de estos elementos, con el propósito de identificar los procedimientos que sus constructores siguieron para determinar sus dimensiones.

\section{RESULTADOS}

\section{ANTECEDENTES DE LAS BÓVEDAS DE NERVADURAS}

El precedente más remoto de las bóvedas de nervaduras o de crucería son las bóvedas de arista romanas generadas por la intersección de dos cañones corridos de la misma altura; su ventaja respecto de sus antecesoras de cañón corrido es que al concentrar su peso hacia puntos específicos solo necesitan apoyos en sus cuatro esquinas (figura 1). Para salvar las dificultades constructivas en las aristas la edificación medieval las cubrió con arcos conocidos como cruceros (Rabasa, 2000, p. 51). Las bóvedas de arista más antiguas tenían arcos frontales semicirculares, con arcos cruceros semielípticos (Esselborn, 1952, p. 183); 

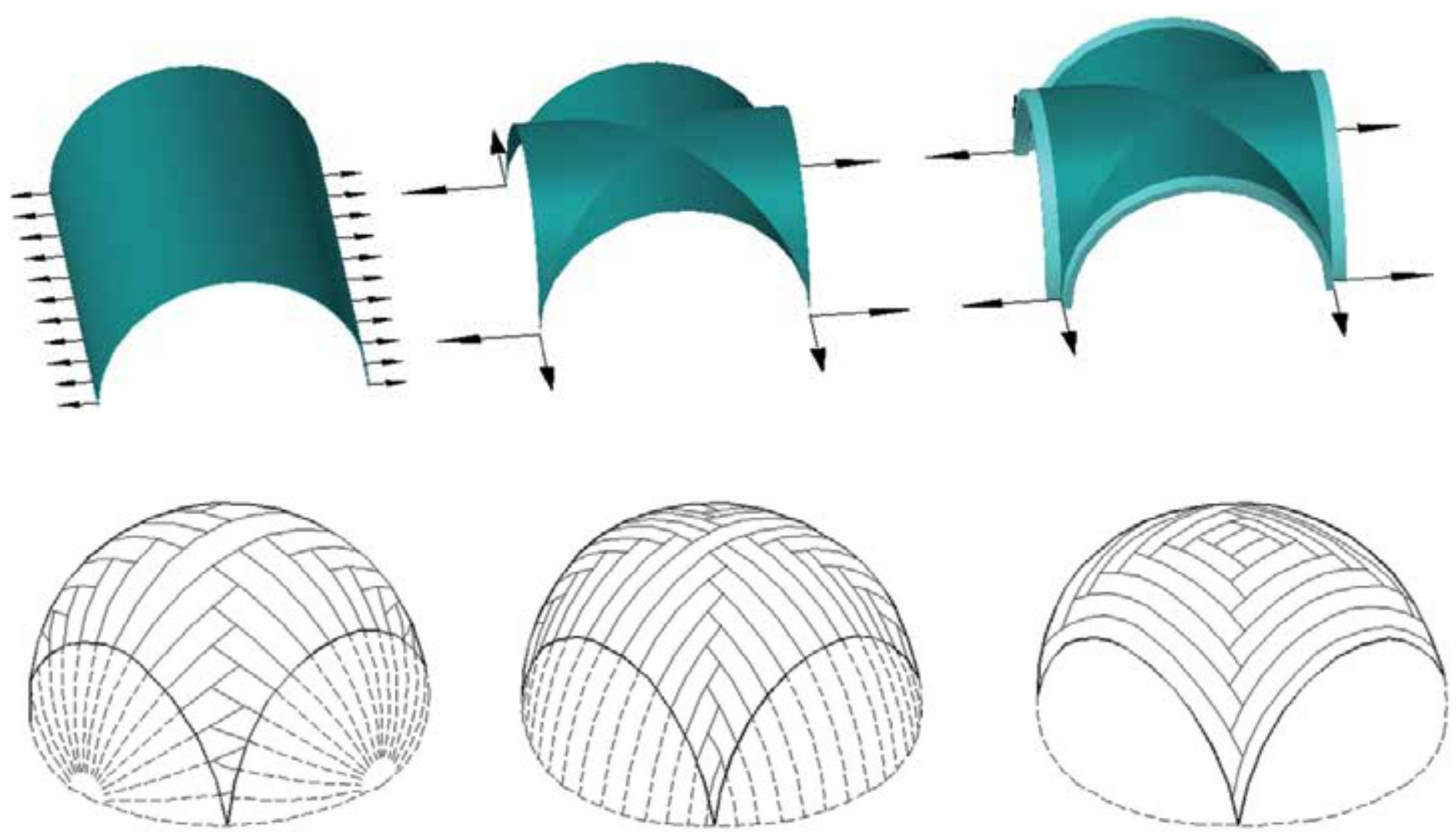

(A) Figura 1.

(A) Distribución del empuje de bóvedas de cañón corrido y bóvedas de arista con y sin arcos Ilustración: N. García.

\section{(A) Figura 2.}

(4) Disposición de las hiladas de mampostería en bóvedas abombadas Fuente:Fitchen (1981). un avance constructivo y estructural de gran relevancia se dio cuando estos arcos se construyeron de medio punto, ya que generan menor empuje que los elípticos y la curvatura de cada dovela no cambia. Rabasa (2000, pp. 51, 54) comenta estos aspectos y señala que el cambio de aristas elípticas a semicirculares marca el inicio de la construcción de bóvedas de nervaduras.

La adopción del semicírculo en los arcos cruceros propició la aparición de cubiertas muy parecidas a las bóvedas vaídas, que en realidad tenían formas abombadas (figura 2) porque su origen fue el de una bóveda de arista y las hiladas no se adaptaban totalmente a una esfera (Fitchen, 1981, p. 59). La aparición de este sistema de cubierta permitió el desarrollo de una gran variedad de formas geométricas en la plementería, que fue ampliamente desarrollada en la España de los siglos XIII al XVI. Fueron muy populares en ese periodo las bóvedas cuatripartitas o de crucería simple, que dividen los témpanos de la bóveda en cuatro partes; Viollet-le-Duc (1996, pp. 105-108) las clasifica según su plementería en bóvedas de estilo francés, aquitano, normando y angevino. Lampérez (1930, p. 470) agregó a esta clasificación la bóveda aquitano-española en la que, a diferencia de las últimas tres, su casquete no tiene una superficie continua en forma de cúpula, sino que los plementos tienen diferente curvatura entre cada par de nervios.

Cuando se construyeron nervaduras adicionales a los arcos perimetrales y cruceros — conocidos como terceletes, ligaduras y combados- ${ }^{1}$, se inició la construcción de las bóvedas de crucería

1 Las ligaduras son nervios secundarios de una bóveda nervada, cuando estos son curvos se llaman combados. estrelladas en Europa. Aunque la más común en España fue la de terceletes con cinco claves (figura 3), también se realizaron numerosas con diseños complicados (Lampérez, 1930, p. 477) consistentes en entramados o mallas que, de acuerdo con Rabasa (2000, p. 70), sirvieron de guía y control de la geometría y no de cimbra, como se ha argumentado por otros autores. En el siglo XVI se construyeron en España formas acupuladas, prácticamente sin aristas y con nervaduras que Navarro (2006, p. 76) describe como nervios sin funcionamiento estructural.

Las bóvedas estrelladas españolas surgieron básicamente de dos escuelas: la toledana y la burgalesa (Palacios, 2003, p. 1548). La primera caracterizada por diseños rectilíneos, y la segunda, por el uso de nervios secundarios curvos o combados. Las geometrías logradas en esas escuelas fueron variadas y han sido clasificadas por Palacios (pp. 1552-56) según la geometría de su rampante $^{2}$ en plano, redondo, esférico, abombado y convexo, además de las bóvedas rebajadas apoyadas en arcos escarzanos o carpanel, que usualmente se encuentran en el sotocoro de las iglesias. Estas bóvedas de nervaduras estrelladas españolas, constituyen "la versión renacentista de las bóvedas europeas de crucería del gótico clásico francés" (Kubler, 1983, p. 272), y son semejantes a las que se construyeron en México durante el siglo XVI.

\section{ASPECTOS BÁSICOS DEL DISEÑO DE LAS BÓVEDAS DE NERVADURAS ESPAÑOLAS Y SUS CONTRAFUERTES}

El tratado español de Rodrigo Gil de Hontañón (1951), escrito entre 1544 y 1554, del que

2 El rampante es la línea o nervadura central que une longitudinalmente las claves de cada tramo. 


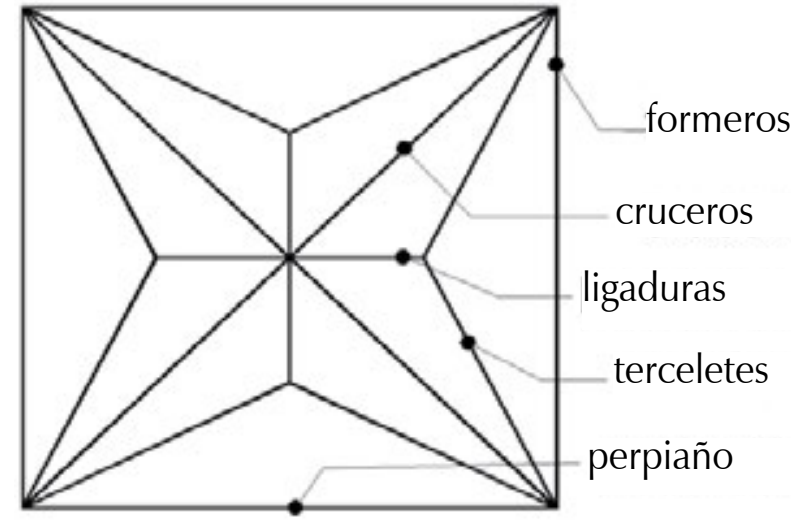

tenemos referencia gracias a la transcripción de Simón García (1991) realizada en 1681, pues el original no se logró conservar; así como el tratado de Hernán Ruiz (Navascués, 1974), redactado entre los años 1558-1560; y los manuscritos de Alonso de Vandelvira (ca. 1591) y del padre Tomás Vicente Tosca (1727), describen métodos para el trazado de bóvedas nervadas (figura 4) mediante la elaboración de monteas ${ }^{3}$. El primero de ellos indica la secuencia constructiva y los otros describen procedimientos para definir la geometría de cada nervio. Estos métodos conocidos como trazo de rampante fijo, han sido estudiados ampliamente por Navarro (2006), Palacios $(2003,2007)$ y Rabasa (2000).

En particular, el trazo de los terceletes en planta solía generarse a partir de tres métodos: uso de redes, uso de alineaciones y puntos de encuentro de trazos geométricos (Palacios, 2003, pp. 154850). De los más comunes en España fue el último de ellos, que consiste en ubicar los terceletes a partir de un círculo circunscrito a la planta de la bóveda y su intersección con los ejes ortogonales.

Rodrigo Gil de Hontañón (1951) desarrolló reglas para establecer las dimensiones de las nervaduras y sus claves, así como de los contrafuertes que soportan bóvedas nervadas. Estableció la jerarquía de cada nervadura conforme a la carga que soportan y propuso el peralte necesario para cada una de ellas. Para determinar las dimensiones de los contrafuertes propuso una regla para bóvedas de nervaduras de iglesias-salón ${ }^{4}$; Sanabria (2003, p. 1797) y Huerta (2004, p. 214) describen esta regla mediante la fórmula que aparece en la tabla 1.

3 La montea es el esquema geométrico que relaciona la planta de la bóveda con la elevación de cada nervio.

4 Iglesia salón: iglesia de disposición basilical, de más de tres naves de la misma altura.
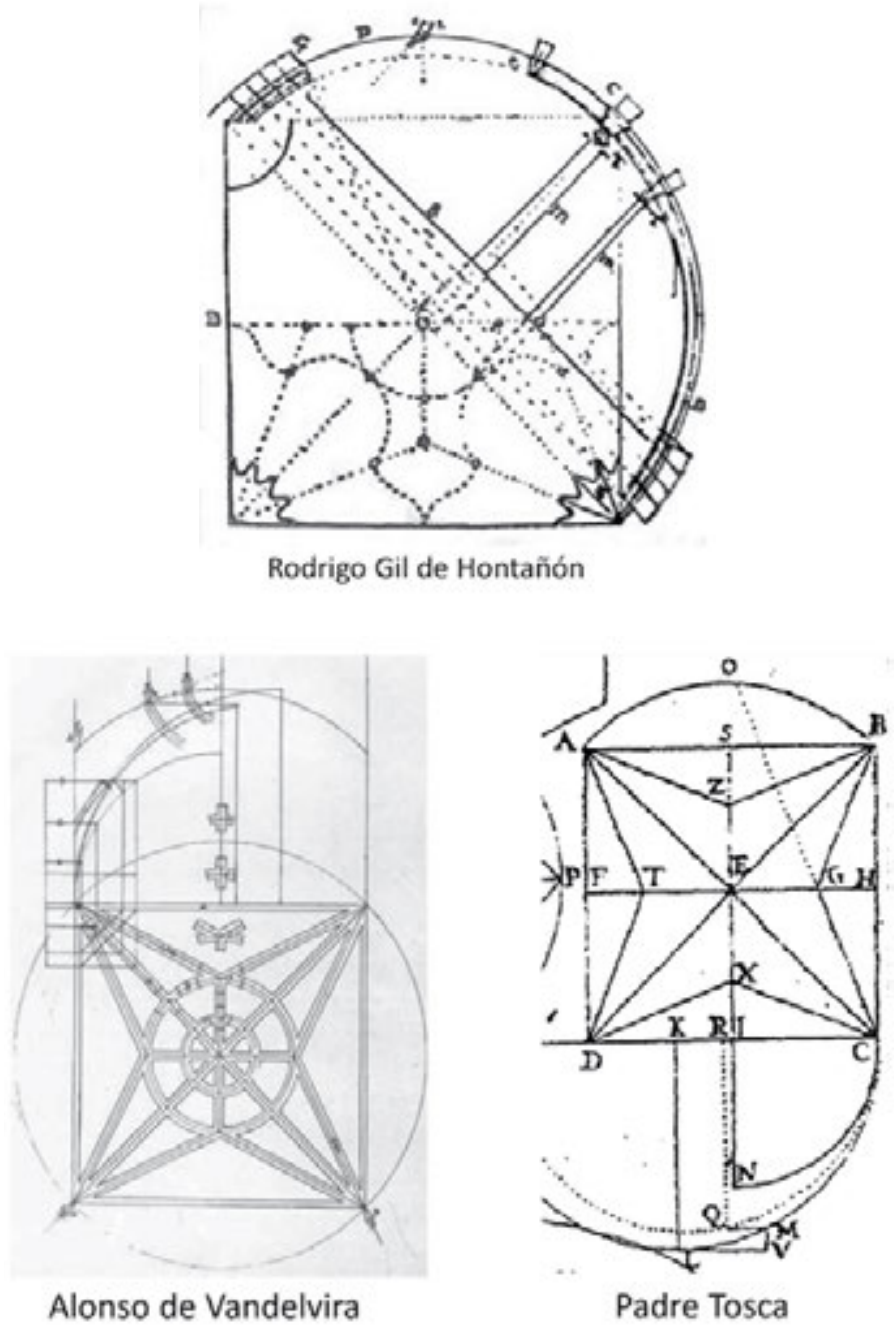

\section{TEMPLOS CONVENTUALES MEXICANOS DEL SIGLO XVI CON BÓVEDAS DE NERVADURAS}

Kubler (1983, pp. 271-275) identificó las características más relevantes de las bóvedas de nervaduras mexicanas construidas en el siglo XVI (tabla $2)$, compuestas por conglomerados de mampostería de grandes espesores, parecidas a las edificadas por Rodrigo Gil de Hontañón en España. Los primeros maestros constructores de estas bóvedas en México fueron fray Juan de Alameda y Claudio de Arciniega (Martínez, 1988, p. 89). Al primero de ellos se le atribuyen las bóvedas de los templos de Huejotzingo, Cholula y Tula, entre otros. Existe la posibilidad de la participación de Claudio de Arciniega en algunos trabajos de construcción en los templos con bóvedas nervadas de Acolman, Metztitlán y Actopan (Cuesta, 2000, p. 87) y de Francisco Becerra en las bóvedas de nervaduras del presbiterio de Cuauhtinchan y Totimehuacan. Fernández (2007, p. 100) considera que Becerra optó por este tipo de cubiertas, tanto en su país de origen como en el continente americano, más por una concepción estructural que de ornamento.

La construcción de templos cubiertos totalmente con este tipo de bóvedas se inició después de la primera mitad del siglo XVI (Kubler, 1983, pp. 269, 270). Hoy en día existen quince templos con estas características, de los que solo uno tiene bóveda de casetones en el presbiterio. En la mayoría, el coro está soportado también por una bóveda de nervaduras plana apoyada sobre arcos escarzanos 
Tabla 1.

Regla de Rodrigo Gil de Hontañón para contrafuertes que soportan bóvedas de nervaduras Fuente: Sanabria (2003, p. 1797); Huerta (2004, p. 214)

Tabla 2.

Características de las bóvedas de nervaduras mexicanas

Fuente: Kubler (1983, pp. 271-275).

> Tabla 3.

Templos mexicanos del siglo XVI cubiertos totalmente con bóvedas de nervaduras

Fuente: datos obtenidos en el sitio, excepto los señalados con los siguientes superíndices: ${ }^{k}$ Kubler (1983, pp. 279, 300)

* Planos del archivo de la Coordinación Nacional de Monumentos Históricos.

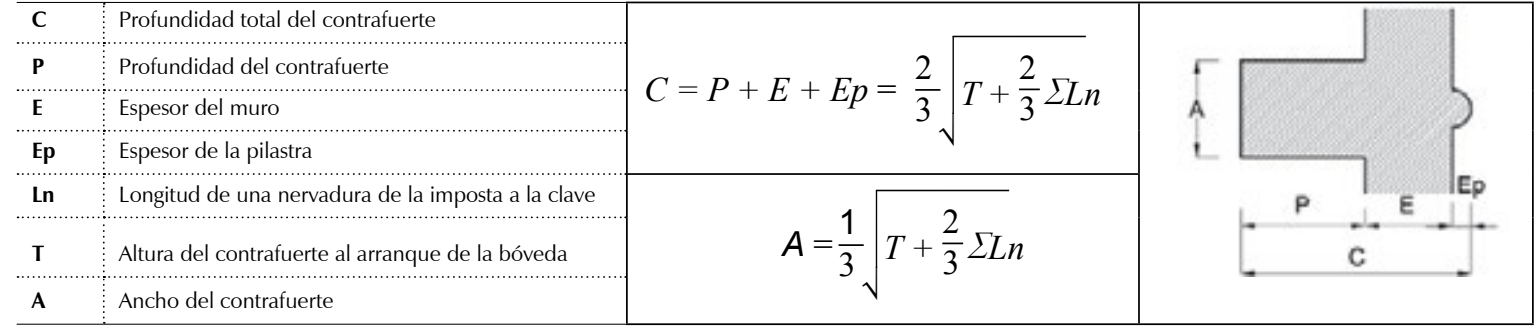

\begin{tabular}{|c|c|c|c|c|c|c|c|c|}
\hline $\begin{array}{c}\text { Periodo } \\
\text { construcción }\end{array}$ & Ubicación & Longitud & Ancho & Altura & $\begin{array}{l}\text { Longitud/ } \\
\text { Ancho }\end{array}$ & $\begin{array}{l}\text { Altura/ } \\
\text { Claro }\end{array}$ & $\begin{array}{l}\text { Profundidad } \\
\text { contrafuerte }\end{array}$ & $\begin{array}{l}\text { Espesor } \\
\text { de muro }\end{array}$ \\
\hline \multicolumn{9}{|c|}{ TEMPLOS FRANCISCANOS } \\
\hline \multirow{2}{*}{$1545-1555$} & Cholula & 53,00 & 12,00 & 20,50 & 4,4 & 1,7 & 3,03 & 1,73 \\
\hline & Tula & 49,50 & 12,00 & 20,30 & 4,1 & 1,7 & 2,87 & 1,78 \\
\hline \multirow{3}{*}{$1555-1560$} & Tecamachalco & --- & -- & $--\cdot$ & --- & -- & -- & --- \\
\hline & Acatzingo & 53,00 & 12,20 & 21,15 & 4,3 & 1,7 & 2,45 & 1,75 \\
\hline & Puebla (Sn Fco.) & $60,00^{k}$ & $13,20^{\mathrm{k}}$ & 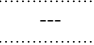 & 4,5 & 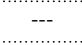 & $2,50^{*}$ & $1,60^{*}$ \\
\hline \multirow{6}{*}{ Después de 1560} & Huejotzingo & $57,45^{*}$ & 13,06 & 22,30 & 4,4 & 1,7 & $3,03^{\mathrm{k}}$ & $2,00^{\mathrm{k}}$ \\
\hline & Huaquechula & $46,30^{k}$ & $11,40^{\mathrm{k}}$ & $19,12^{\mathrm{k}}$ & 4,0 & 1,7 & $2,80^{*}$ & $1,60^{*}$ \\
\hline & Tochimilco & 48,30 & 11,98 & 20,98 & 4,5 & 1,8 & 2,70 & 1,90 \\
\hline & Zempoala & $50,50^{k}$ & $12,50^{k^{\prime \prime}}$ & $21,40^{*}$ & 4,0 & 1,7 & $2,35^{*}$ & $1,50^{*}$ \\
\hline & Atlixco & $43,20^{k}$ & $11,00^{k}$ & 17,90 & 3,9 & 1,6 & --- & --- \\
\hline & Tepeaca & $53,60^{k}$ & $12,80^{\mathrm{k}}$ & $21,70^{k}$ & 4,2 & 1,7 & $1,80^{*}$ & --- \\
\hline \multicolumn{9}{|c|}{ TEMPLOS DOMINICOS } \\
\hline Después 1550 & 12. Coixtlahuaca & --- & $12,50^{*}$ & --- & --- & --- & --- & --- \\
\hline Después 1561 & 13. Oaxtepec & 53,46 & 11,26 & 15,80 & 4,8 & 1,4 & 1,70 & 1,90 \\
\hline ca. 1558 & 14. Tlaxiaco & $50,40^{*}$ & $11,75^{*}$ & $--\cdot$ & 4,1 & 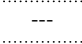 & $1,20^{*}$ & $1,70^{*}$ \\
\hline Después 1550 & 15. Yanhuitlán & $59,20^{*}$ & $14,20^{*}$ & $26,00^{*}$ & 4,2 & 1,8 & $2,00^{*}$ & $1,60^{*}$ \\
\hline
\end{tabular}

o de tipo carpanel. Más de la mitad de estos templos perteneció a la orden franciscana y fueron construidos en el estado de Puebla; los restantes fueron dominicos, tres de ellos en Oaxaca y uno en Morelos. Los agustinos también emplearon este tipo de bóveda pero solo para cubrir el presbiterio de sus templos, una sección de la nave o el sotocoro; las usaron también para techar los pasillos de algunos claustros de sus conventos, en mayor número que los franciscanos y dominicos. Asimismo, podemos encontrar estas bóvedas en algunas capillas abiertas y capillas posas.

Las iglesias enumeradas en la tabla 3 son de nave única y la proporción de su longitud en planta respecto del claro de la nave está entre 4 y 4,5 . Solo el templo de Oaxtepec, que cuenta con "corillos"5 (Artigas, 2011, p. 347), tiene relación longitud-claro de poco más de 5, proporción recomendada por Rodrigo Gil de Hontañón para iglesias con crucero (Gil de Hontañón, 1951, p. 13). La tabla 3 muestra los edificios

5 Los corillos son espacios adosados a uno central que servían de coros pequeños para cantores (Artigas, 2011, p. 347). franciscanos ordenados según la etapa de construcción que propone Kubler (1983, p. 275); se observa que la proporción altura-claro de la nave es cercana a 1,7 en la mayoría de estos templos, independientemente del periodo de construcción. Esto no sucede en las iglesias dominicas, entre las que se encuentran las de mayor y menor esbeltez de todos los templos techados totalmente con bóvedas nervadas.

\section{TRAZO DE BÓVEDAS NERVADAS Y SUS CONTRAFUERTES EN MÉXICO}

Para el estudio detallado del trazo de las bóvedas se eligieron las iglesias conventuales ubicadas en Cholula, Tula, Acatzingo y Oaxtepec (figura 5), de las que se contó con un levantamiento previo realizado por una empresa mediante equipo escáner láser. Los tres primeros templos pertenecieron a la orden franciscana; dos ubicados en el estado de Puebla y uno en Hidalgo. El último perteneció a la orden dominica y se encuentra en el estado de Morelos. Dos de ellos se construyeron en el periodo de 1545 a 1555; el tercero de los templos 

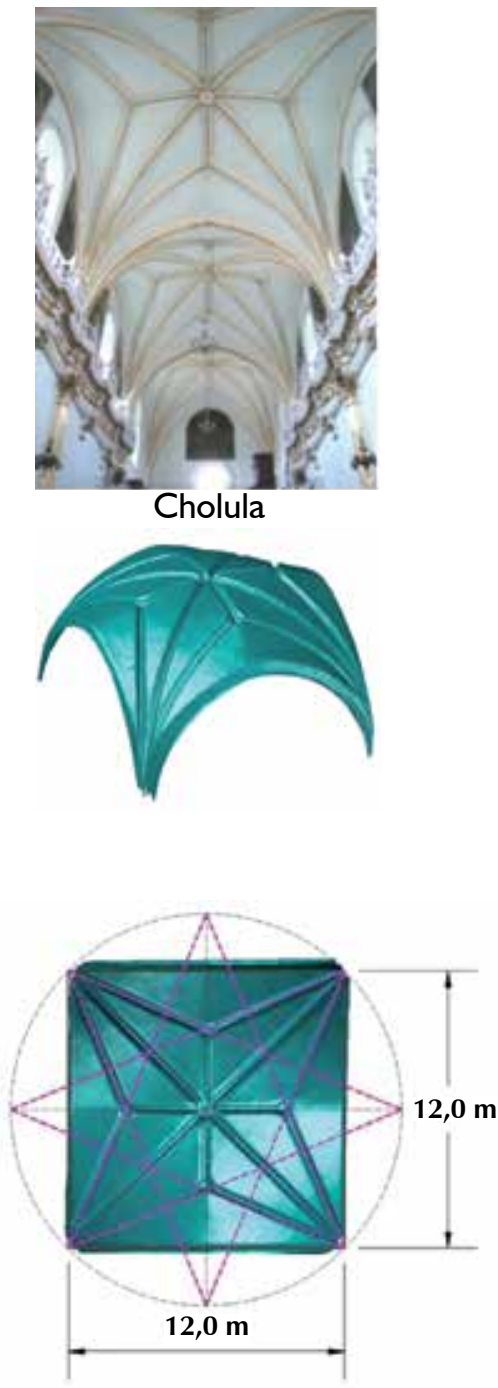

Cholula

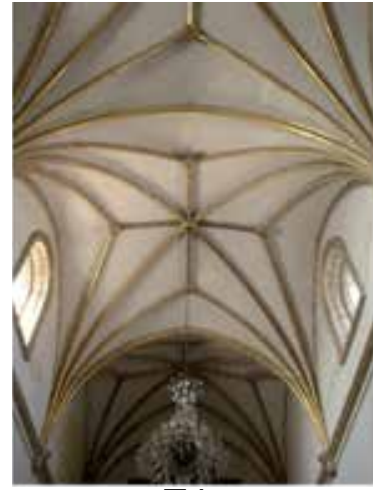

Tula
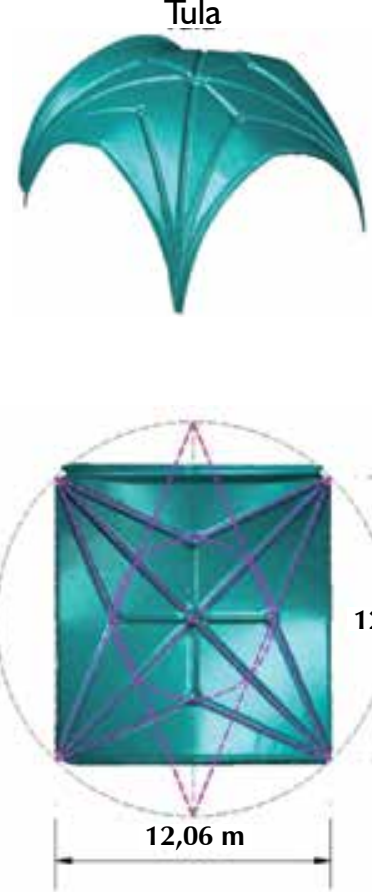

Tula
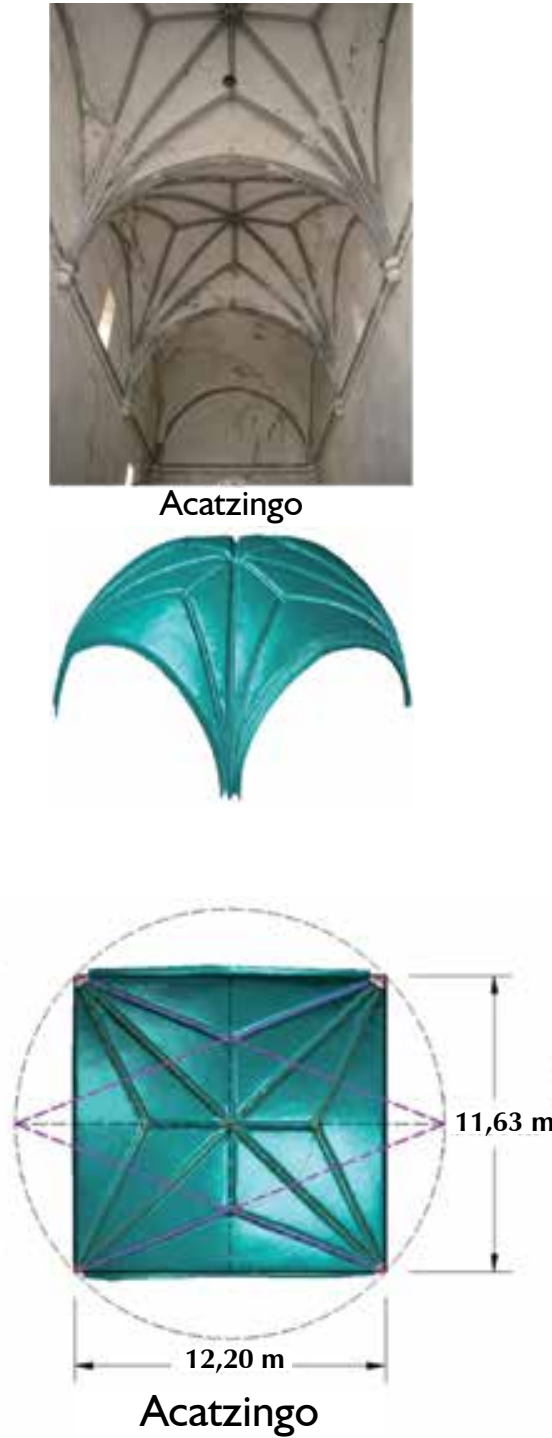

Acatzingo
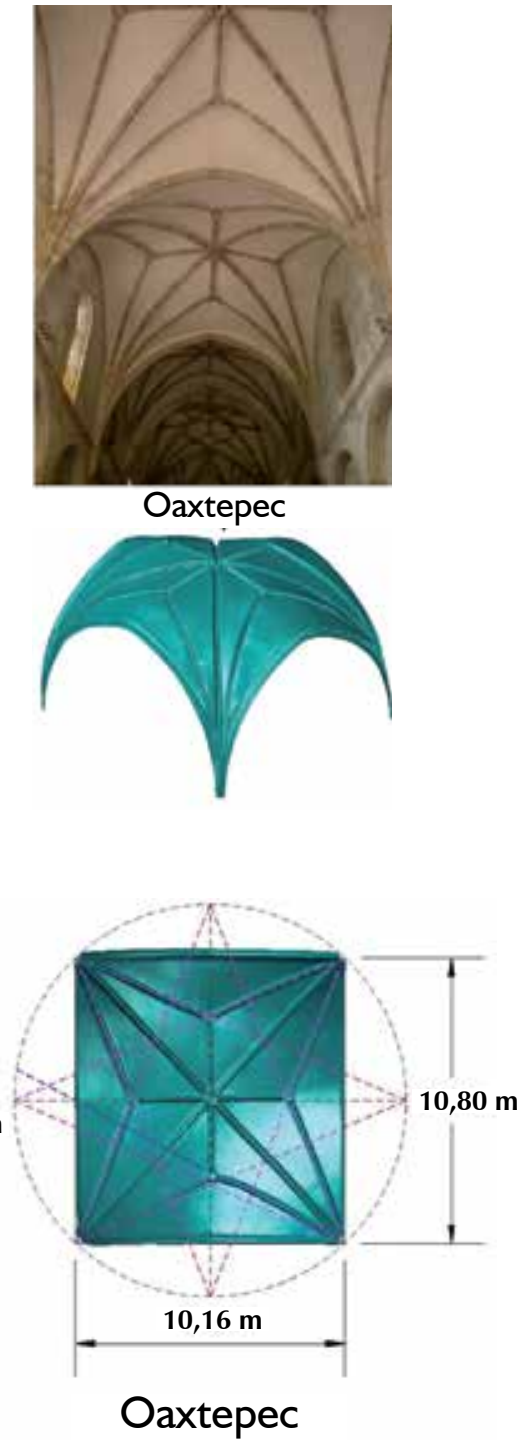

Oaxtepec corresponde al periodo de 1555 a 1560, y el último es posterior a 1560. Estas iglesias tienen diferencias geométricas en el contorno de su extradós, en la geometría de sus rampantes y en su plementería. Se comparó su geometría con la obtenida mediante las reglas de los tratados de Alonso de Vandelvira (1575-1580) y el padre Tosca (1707-1715). Para el estudio de las dimensiones de los contrafuertes que soportan estas bóvedas se recurrió a los tratadistas españoles Rodrigo Gil de Hontañón (1951), Martínez de Aranda (ca. 1599) y Hernán Ruiz (Navascués, 1974). Si bien todos estos tratados no fueron conocidos por los constructores de estos templos, ya que llegaron al continente americano después del periodo que aquí se estudia, su contenido refiere a la práctica constructiva española de esa época y anterior ${ }^{6}$, muy probablemente conocida por los constructores de los edificios conventuales mexicanos.

\section{TRAZO DE LOS TERCELETES EN PLANTA}

La planta de cada crujía de los cuatro templos estudiados es ligeramente rectangular. El estudio de los terceletes consistió en dibujar en cada planta los métodos propuestos por los tratadistas. En la figura 6 es claro el uso del método de "encuentro

6 Huerta $(2004$, p. 141) señala que algunas reglas de los tratados surgidos en un periodo histórico pueden tener su origen en la tradición constructiva de siglos pasados y que no fueron dadas a conocer en su momento por la reserva que guardaban los antiguos constructores de sus conocimientos en edificación. entre puntos" del tratado del padre Tosca en los templos de Cholula y Oaxtepec. Solo un tercelete de la parte inferior izquierda de Oaxtepec coincide con el procedimiento dado por Vandelvira, al parecer más por imperfecciones en la mano de obra y no por cambio de diseño. El estudio de los terceletes de la bóveda del templo de Cholula se hizo a partir de una planta cuadrada de doce metros de lado, solo para hacer coincidir los nervios cruceros en el centro de la planta, ya que en realidad la crujía es ligeramente rectangular. En los templos de Acatzingo y Tula solo cuatro de sus ocho terceletes siguen el trazo de "encuentro entre puntos". Uno en sentido transversal a la nave y el otro solo en sentido longitudinal. El resto de sus terceletes se obtiene mediante un círculo con centro en la clave de los cruceros, y diámetro igual a la distancia que hay entre los terceletes trazados previamente (figura 6).

\section{TRAZO DE LAS NERVADURAS EN ELEVACIÓN ${ }^{7}$}

El rampante y el perfil transversal de tres de las cuatro bóvedas estudiadas coinciden con un semicírculo que tiene su centro en la intersección de los nervios cruceros en planta (figura 7). Aunque las ligaduras no siguen perfectamente esta curvatura, sí se adaptan a ella en lo general. Solo el templo de Oaxtepec tiene ligaduras prácticamente rectas que recuerdan la escuela toledana,
(A) Figura 5 .

(A) Intradós de las bóvedas de las iglesias de Cholula, Tula, Acatzingo y Oaxtepec

Foto: N. García, 2011

(A) Figura 6

(A) Trazo de los terceletes en planta de los templos conventuales

Ilustración: N. García. 


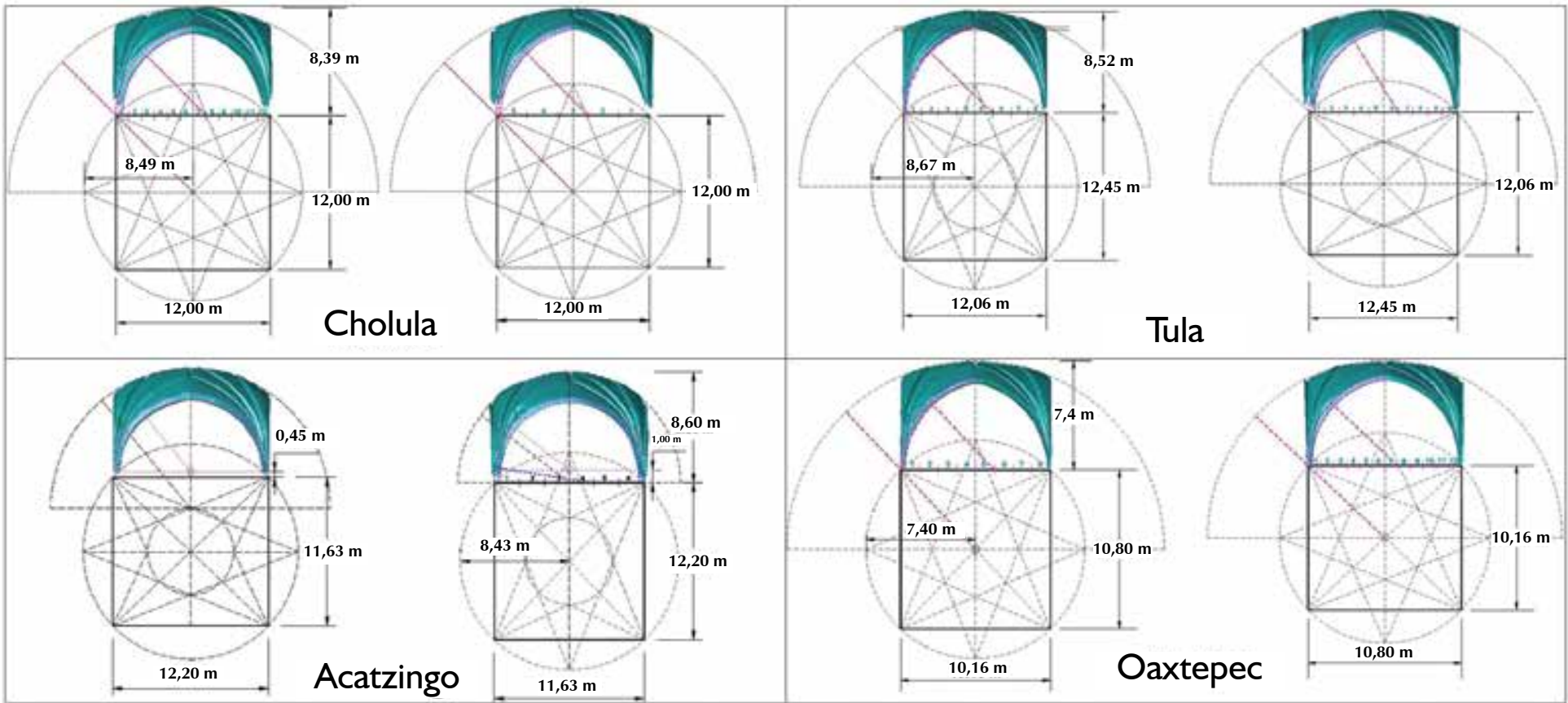

(A) Figura 7.

Trazo de los nervios formeros, perpiaños y ligaduras

Ilustración: N. García.

\section{Figura 8 .}

Extradós de las iglesias de nervaduras del siglo XVI en México

Fotos: N. García, 2011.
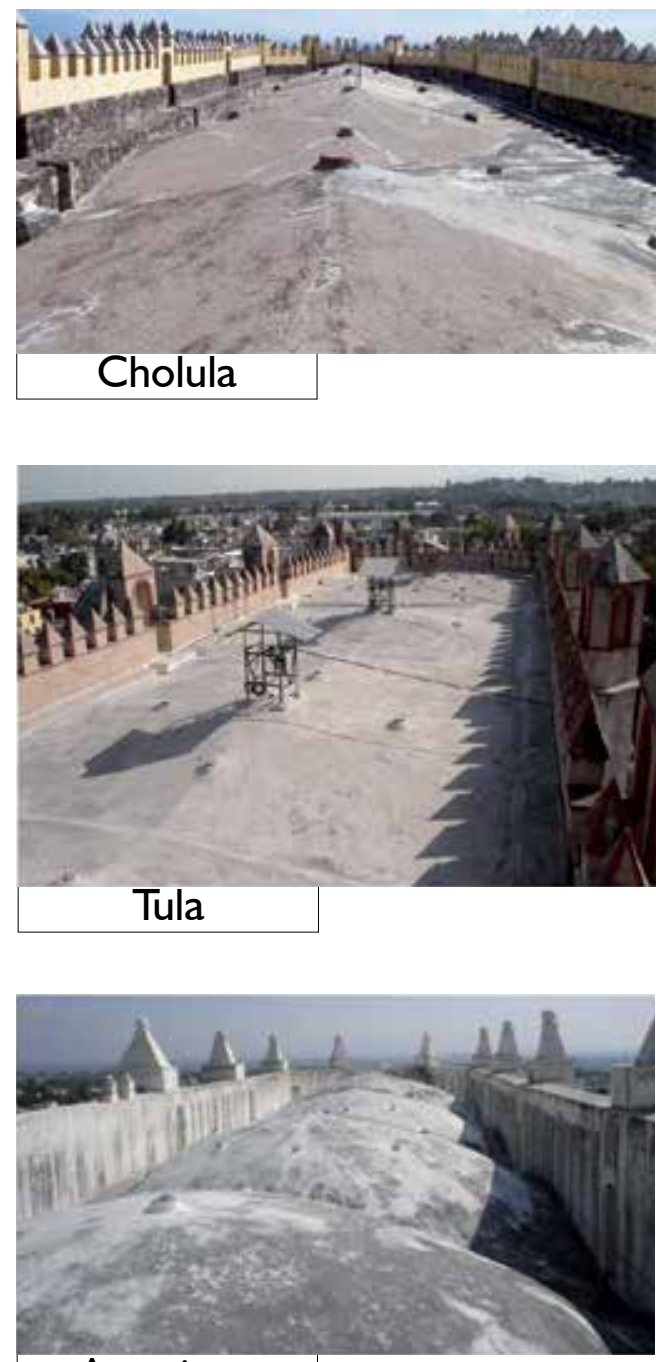

Acatzingo

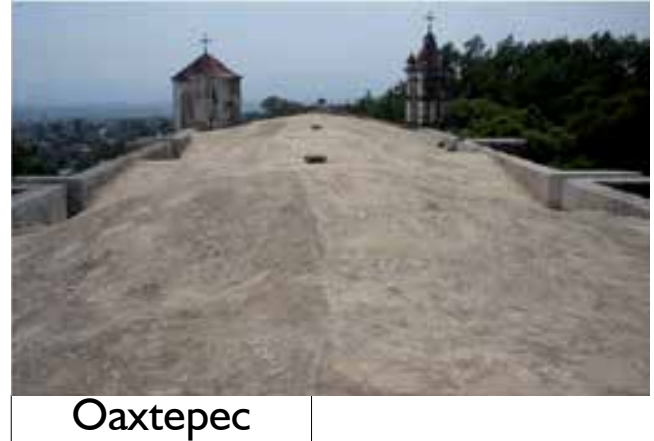

a diferencia de las primeras tres, que están más cerca de la escuela burgalesa por la presencia de combados o ligaduras curvas. En este último caso, la apariencia es más parecida a la de bóvedas vaídas, particularmente las bóvedas de los templos de Acatzingo y Tula.

En la figura 7 se observa que los arcos perpiaños y formeros tienen la misma flecha en cada caso, solo en la iglesia de Tula la clave de sus arcos formeros está un poco más abajo que la de los perpiaños. Los arcos perimetrales de los cuatro templos son ligeramente apuntados, excepto los de la iglesia de Acatzingo, que tienen perfil semicircular. En este caso se realizaron dos propuestas para el estudio del origen de su trazo; una de ellas consiste en iniciar los arcos por encima de la línea de arranque de los nervios y definir los arcos formeros mediante dos arcos tangentes semicirculares $^{8}$ (Bechmann, 1991, en Rabasa, 2000, pp. 61, 62). El perfil de los arcos perimetrales de los otros templos se logra dividiendo el claro en varios tramos iguales, a nivel de los arranques de los haces de nervaduras. El número de estas divisiones no coincide en todos los casos, porque tienen la misma flecha y el claro de los arcos perpiaños y formeros es diferente.

En la figura 9 se observa que el trazo de los nervios cruceros de los cuatro templos sigue el método del tratado del padre Tosca. Solo la bóveda de Acatzingo tiene arcos cruceros con ligero apuntamiento, y en la de Oaxtepec, un descenso leve en la clave. Por su parte, el trazo de los terceletes en los templos de Cholula y Tula coincide más con el método del tratado de Vandelvira. En cambio, los terceletes de la iglesia de Acatzingo están más cercanos a la curvatura de sus nervios cruceros y no siguen ninguno de los dos tratados. Lo mismo sucede en los de la iglesia de Oaxtepec, pero el radio de la curvatura de sus terceletes es menor que el de los cruceros. 


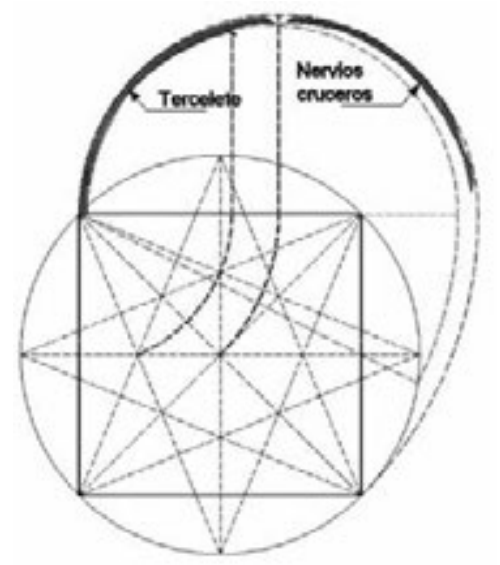

Cholula

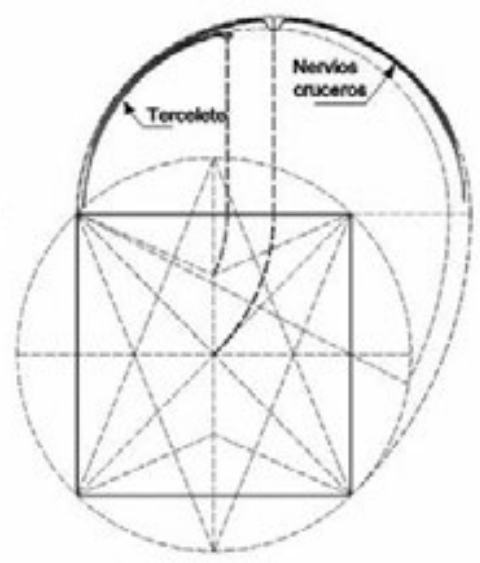

Tula

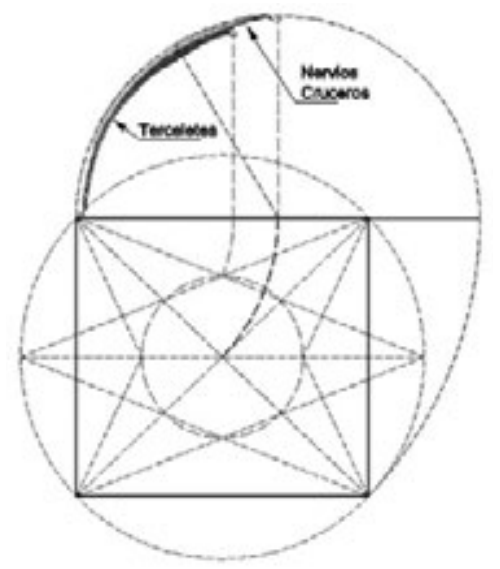

Acatzingo

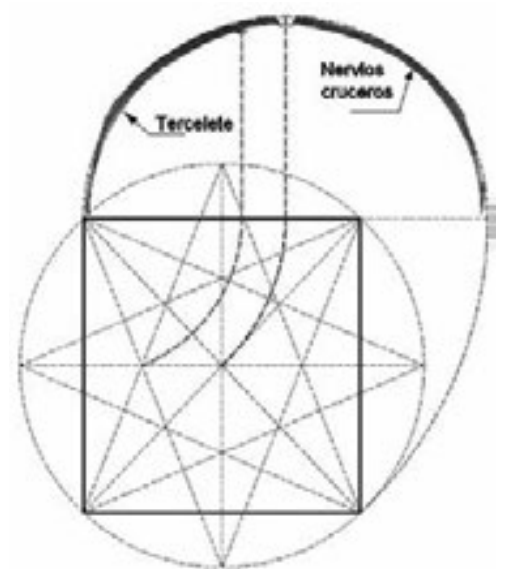

Oaxtepec

\section{GEOMETRÍA DEL EXTRADÓS Y PLEMENTERÍA DE BÓVEDAS NERVADAS}

Durante el siglo XVI se dieron diversas soluciones al perfil del extradós de las bóvedas de nervaduras (Kubler, 1983, p. 271). Algunas tienen techos casi planos, con los riñones totalmente cargados, en los que solo sobresale la cumbre de la bóveda, como en las bóvedas de Cholula y Tula; otras cuentan con extradós prácticamente libre de relleno que tiene geometría cupuliforme, como las bóvedas del templo de Acatzingo; en un tercer grupo se ubican las de perfil ondulado (figura 8), como las bóvedas de Oaxtepec, Tepeaca y Tochimilco, entre otras.

Desde el punto de vista estructural, la recomendación de "cargar los riñones" de las bóvedas, descrita en antiguos tratados de construcción, les da mayor estabilidad (Meli, 2011, p. 117) y fue práctica común. De los templos estudiados solo la bóveda de Acatzingo no tiene sus riñones cargados y el espesor de su cumbrera, de $50 \mathrm{~cm}$ aproximadamente, es el menor de todos. La geometría de su plementería es la que más se acerca a la de una bóveda vaída. Esto puede observarse en la figura 10, donde se muestra un corte a la altura de la clave de los arcos perimetrales, paralelo a la planta de las cuatro bóvedas estudiadas aquí. Al igual que la bóveda del templo de Acatzingo, la de Tula se aproxima a la geometría de una bóveda vaí$\mathrm{da}$, pero se aleja en la zona de sus arcos perpiaños donde la plementería forma una especie de lunetos. Artigas (2011, p. 341) clasifica a este tipo de bóvedas como renacentistas, por sus características geométricas, en las que predomina la forma esférica. De hecho, la bóveda del coro del templo de Acatzingo, carente de nervaduras, nos indica que su geometría en forma de cúpula le proporciona estabilidad por sí sola. Por el contrario, siguiendo a este mismo autor, las bóvedas de los templos de Cholula y Oaxtepec estarían más cerca de la "filiación gótica" (p. 341), que consiste de nervaduras sobre las que se apoya la plementería. Esta característica se muestra más claramente en la bóveda del coro del templo de Oaxtepec, a diferencia del resto de las crujías en las que los cambios de curvatura son menos pronunciados (figura 11).
El recubrimiento de esta bóveda muestra un despiece de doble arista ${ }^{9}$, común en las bóvedas estrelladas españolas (Navarro, 2004, p. 186).

\section{MUROS Y CONTRAFUERTES}

En esta sección se estudian las características geométricas de los contrafuertes sobre los que se apoyan las bóvedas de nervaduras. Estos elementos están ubicados a todo lo largo de los muros laterales y su función consiste en contrarrestar el empuje generado por las bóvedas; de ahí su importancia para la estabilidad del edificio. Estos elementos estructurales son de grandes dimensiones, sobre todo en la fachada longitudinal opuesta al convento, debido a que la retícula de muros de este último contribuye a su estabilidad; sin embargo, en ocasiones el contrarresto en la zona superior del templo por encima de la altura del convento no fue bien resuelto, dando por resultado algunos agrietamientos en la bóveda (Meli, 2011, p. 118).

En este estudio se ha comparado la profundidad real de estos elementos de soporte ubicados en el muro longitudinal opuesto al convento, con la dimensión que resulta de aplicar la regla desarrollada por Rodrigo Gil de Hontañón (1951) (tabla 1) para contrafuertes de bóvedas de crucería en iglesias-salón. El canto total o profundidad del contrafuerte obtenido con esta fórmula incluye el espesor de la pilastra, que no tiene ninguno de los edificios estudiados aquí; por ello, en su lugar se tomó en cuenta el enjarje o repisón al que llegan los haces de nervaduras. En la tabla 4 se muestran los resultados obtenidos en los cuatro templos estudiados en este trabajo. Se observa que las dimensiones del contrafuerte de las iglesias de Acatzingo y Tula están muy cercanas a la regla de Hontañón; cabe mencionar que los contrafuertes de la iglesia de Tula tienen planta pentagonal y los de Acatzingo rectangular. Por su parte, las dimensiones de los contrafuertes del templo

9 El despiece por doble arista consiste en cubrir la bóveda con el método de arista simple entre los terceletes y los arcos perimetrales, y el espacio entre terceletes y ligaduras mediante una disposición romboidal, de manera que las hiladas son ortogonales a los arcos cruceros.

\section{(A) Figura 9. \\ Trazo de los nervios cruceros y terceletes} Ilustración: N. García. 


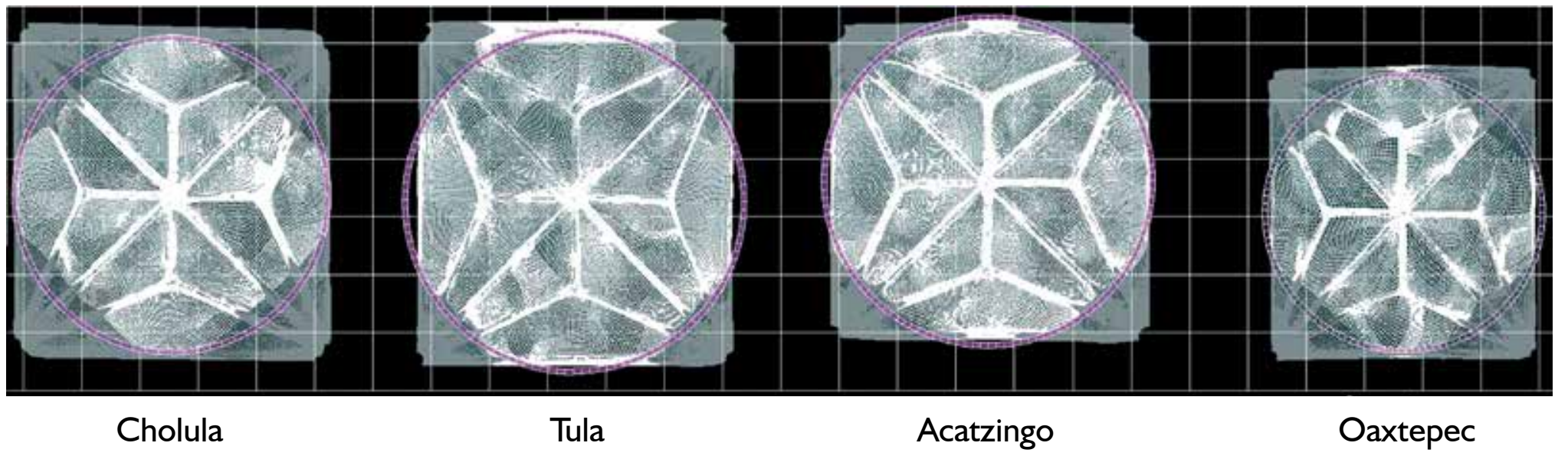

\section{(a) Figura 10.}

Corte de las bóvedas nervadas a la altura de la clave de los arcos perimetrales

Ilustración: N. García.

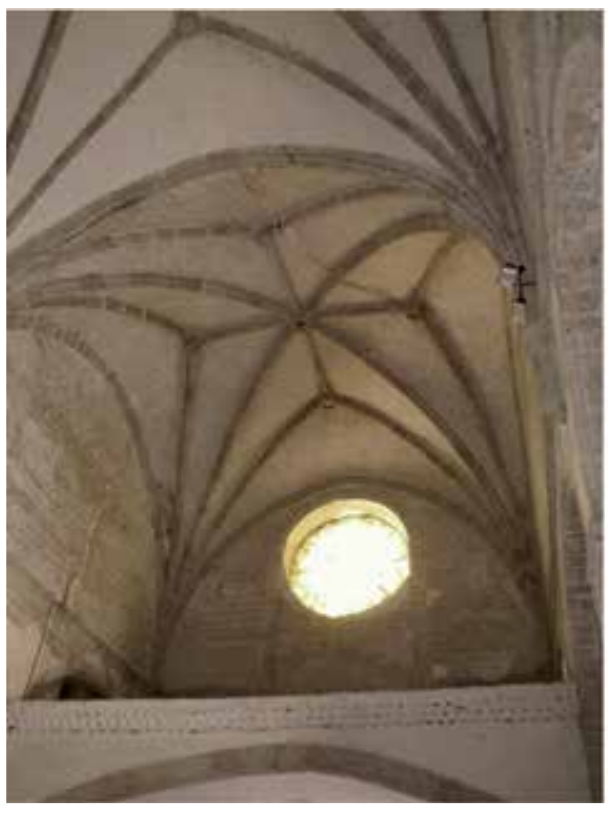

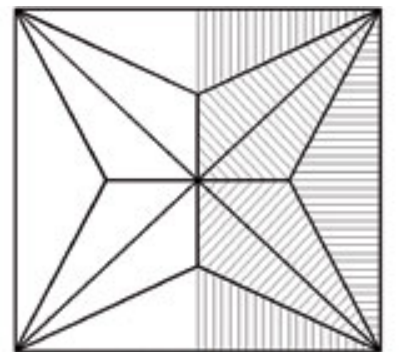

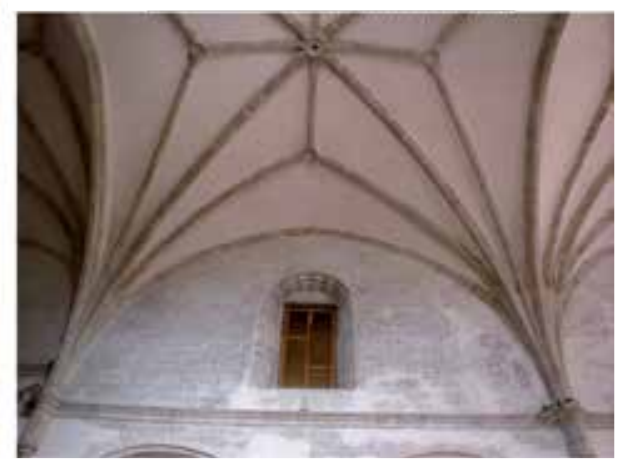

(A) Figura 11.

Bóvedas del coro y de la nave del templo de Oaxtepec

Fotos N. García, 2011 de Cholula son las más conservadoras, mayores que las obtenidas con la regla.

Solo los contrafuertes de la iglesia de Oaxtepec son de mucho menor proporción que los dados por la regla de Hontañón. Para su estudio se optó por revisar otras dos reglas geométricas de la época a fin de determinar el contrafuerte necesario para bóvedas de nervaduras (Huerta, 2004, pp. 141-151). Estas dos reglas estudiadas tienen su origen en el gótico; una corresponde al manuscrito de Martínez de Aranda (ca. 1599) y la otra al de Hernán Ruiz (Navascués, 1974), ambas del siglo XVI. La primera de ellas es conocida también como regla de Blondel (1675) y existe la posibilidad de su uso en naves de crucería en España, Francia y Alemania. Huerta (2004, p. 148) la aplicó en la catedral de Gerona y la Saint-Chapelle de París, logrando resultados coincidentes. Sin embargo, aclara que esto no significa que fuera usada, sino que demuestra el carácter gótico de esas iglesias. Algo semejante ocurre con la iglesia de Oaxtepec (figura 12), cuyos contrafuertes se alejan de las proporciones de los otros tres templos estudiados aquí, y están más cerca de estas dos reglas, sobre todo de la del tratadista Hernán Ruiz.

\section{CONCLUSIONES}

Las bóvedas de nervaduras estudiadas en este trabajo siguen el trazo propuesto en los tratados de Alonso de Vandelvira y el padre Tosca, aunque no literalmente. En algunas de estas bóvedas se toman en cuenta las reglas mencionadas para diseñar los terceletes, y en otras solo en la montea. El trazo en alzado de las bóvedas estudiadas tiene como base el semicírculo en los arcos cruceros y terceletes, con arcos perpiaños y formeros ligeramente apuntados en su mayoría, excepto en aquella que tiende más a la geometría de una bóveda vaída. Si bien se observan diversos lineamientos de la práctica constructiva española, sus constructores tuvieron que adaptarse a condiciones diferentes a las de su país de origen. Los largos periodos de construcción, la variación en las condiciones demográficas, y la disponibilidad de los materiales y mano de obra, entre otros aspectos, pudieron contribuir a que se encuentren algunas diferencias relevantes en la geometría de las bóvedas de cada crujía en la nave de un mismo templo.

Por otra parte, los contrafuertes de mayores dimensiones se acercan a la regla de Rodrigo Gil de Hontañón. Dos de las bóvedas que soportan estos contrafuertes tienen características renacentistas por su aspecto esférico. Por otro lado, tenemos como muestra un templo cuyos contrafuertes son mucho más esbeltos y que están cercanos a la regla de origen gótico de Hernán Ruiz. Esto puede ser un indicativo de que al inicio del periodo virreinal en México se construyeron templos más conservadores en las dimensiones de los elementos estructurales que sustentan bóvedas de nervaduras, y en el último periodo del siglo XVI se optó por el ahorro de material con dimensionamientos menores en sus elementos de soporte. 
Tabla 4.

Reglas históricas aplicadas en los contrafuertes de templos conventuales mexicanos

\begin{tabular}{|c|c|c|c|c|c|c|c|c|c|c|}
\hline \multicolumn{9}{|c|}{ TEMPLO CONVENTUAL } & \multicolumn{2}{|c|}{ REGLA } \\
\hline Ubicación & $L$ & $\mathrm{H}$ & $T$ & $E$ & $P$ & $\mathrm{C}$ & A & Ep & C & $A$ \\
\hline Acatzingo & 12,20 & 21,15 & 12,48 & $2,15^{*}$ & 2,45 & 4,60 & 2,33 & 54,48 & 4,56 & 2,28 \\
\hline Cholula & 12,00 & 20,00 & 11,30 & 1,73 & 3,03 & 4,76 & 3,03 & 53,24 & 4,55 & 2,27 \\
\hline Tula & 12,06 & 20,00 & 11,50 & 1,78 & 2,87 & 4,65 & 2,35 & 55,43 & 4,61 & 2,30 \\
\hline Oaxtepec & 10,16 & 15,70 & 8,45 & 1,90 & 1,70 & 3,60 & 1,72 & 47,58 & 4,19 & 2,10 \\
\hline
\end{tabular}

* Incluye espesor de muro y repisón. $\mathrm{L}=$ Claro de la nave, $\mathrm{H}=$ Altura de la nave, $\mathrm{T}=$ Altura al arranque de las bóvedas, $\mathrm{E}=$ Espesor de muro, $\mathrm{P}=$ Profundidad del contrafuerte, $\mathrm{Ep}=$ Espesor de la pilastra, $\mathrm{A}=$ Ancho del contrafuerte, $\mathrm{C}=\mathrm{E}+\mathrm{P}+\mathrm{Ep}$.

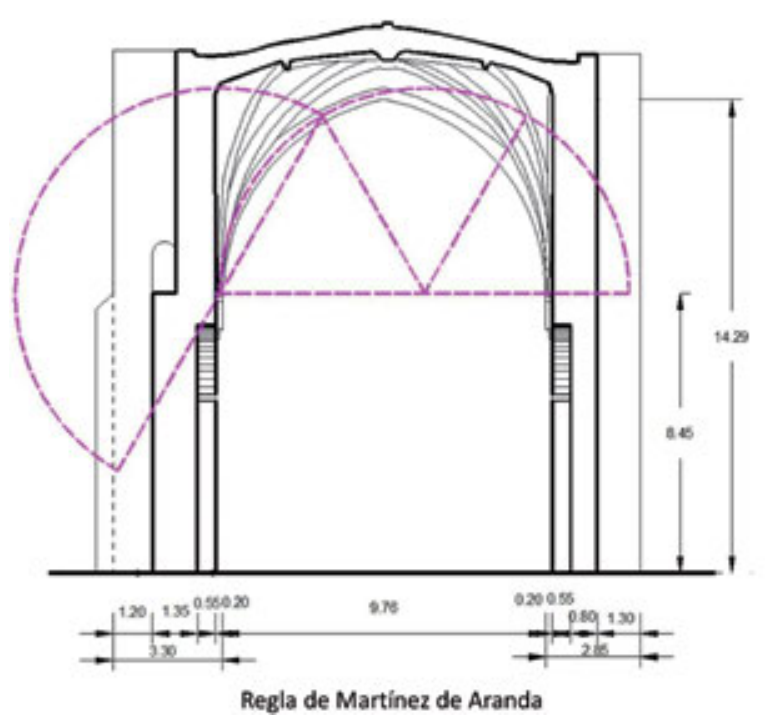

REFERENCIAS

Artigas, J. B. (2011). México, Arquitectura del siglo XVI. México, D. F.: Taurus.

Cuesta, L. J. (2000). Sobre el estilo arquitectónico de Claudio de Arciniega. Anales del IIE, XXII, (76), 61-68.

Esselborn, C. (1952). Tratado general de construcción. Construcción de edificios. Tomo I. (8 ed.). Buenos Aires: Gustavo Gili.

Fernández, Y. (2007). Líneas y modelos arquitectónicos en la obra americana de Francisco Becerra. En Navarro Antolín, F. Orbis incognitvs: avisos y legajos del Nuevo Mundo: homenaje al profesor Luis Navarro García (vol. 2, pp. 93-101). Huelva: Universidad de Huelva.

Fitchen, J. (1981). The construction of Gothic cathedrals: a study of medieval vault erection. (2a ed.). Chicago: University of Chicago.

García, N. y Meli, R. (2009). On structural bases for building the Mexican convent churches from the sixteenth century. International Journal of Architectural Heritage, 3, 24-51, DOI: 10.1080/15583050701842344. URL: http:// dx.doi.org/10.1080/15583050701832344.

García, S. (1991). Compendio de architectura y simetría de los templos conforme a la medida del cuerpo humano, con algunas demostraciones de geometría, año 1681. Valladolid: Colegio Oficial de Arquitectos de Valladolid.

Gil de Hontañón, R. (1951). Rodrigo Gil de Hontañón. Selección y estudio de Manuel Pereda de la Reguera. Santander: Librería Moderna.

Huerta, S. (2004). Arcos, bóvedas y cúpulas. Geometría y equilibrio en el cálculo tradicio-

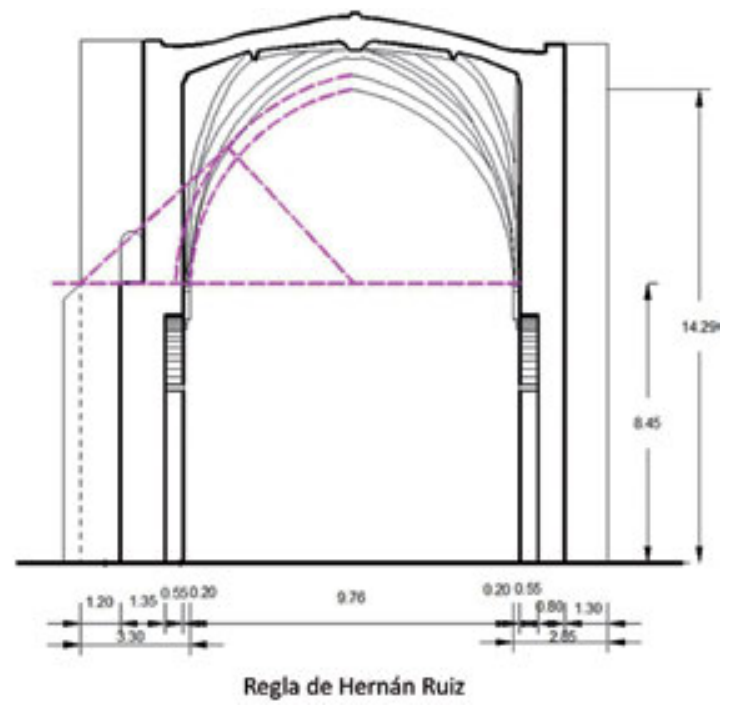

(A) Figura 12

Reglas geométricas para determinar el contrafuerte de bóvedas nervadas en el templo de Oaxtepec Imagen: N. García. nal de estructuras de fábrica. Madrid: Instituto Juan de Herrera y ETSA.

Kubler, G. (1983). Arquitectura mexicana del siglo XVI. (3 3 ed.). México, D. F.: Fondo de Cultura Económica.

Lampérez, V. (1930). Historia de la arquitectura cristiana española en la Edad Media. Madrid: Espasa-Calpe.

Martínez, M. (1988). Los conventos franciscanos poblanos y el número de oro. (Disertación doctoral, Universidad Nacional Autónoma de México, 1987). Puebla, México: Gobierno del estado de Puebla, Centro Regional de Puebla y Fundación Fuad Abed Halabi.

Martínez de Aranda, X. (ca. 1599). Zerramientos i trazas de montea. Recuperado de http://dicter.eusal.es/?obra $=$ MartinezDeAranda

Meli, R. (2011). Los conventos mexicanos del siglo $X V I$. Construcción, ingeniería estructural y conservación. México, D. F.: UNAM y Miguel Ángel Porrúa

Navarro, J. C. (2004). Bóvedas valencianas de crucería de los siglos XIV al XVI. Traza y montea. Tesis de Doctorado para obtener el título de Doctor en Historia del Arte, Facultad de Geografía e Historia, Universidad de Valencia, España.

Navarro, J. C. (2006). Bóvedas de la arquitectura gótica valenciana. Valencia: Universidad Politécnica de Valencia.

Navascués, P. (1974). El Libro de Arquitectura de Hernán Ruiz, el Joven. Madrid: ETSAM. Recuperado de http://oa.upm.es/6641/1/Navascues 12.pdf
Palacios, J. C. (2003). Spanish ribbed vaults in the 15th and 16th centuries. En Huerta, S., De Herrera, J., SEdH, ETSAM, Benvenuto, A. E., COAM, Dragados, F. (eds.), Proceedings of the First International Congress on Construction History (pp. 1547-1558). Madrid.

Palacios, J. C. (2007). Juan de Álava: las bóvedas de crucería reticulares. En Arenillas, M., Segura, C., Bueno, F., Huerta, S. (eds.), Actas del Quinto Congreso Nacional de Historia de la Construcción (pp. 725-732). Madrid.

Rabasa, E. (2000). Forma y construcción en piedra. De la cantería medieval a la estereotomía del siglo XIX. Madrid: Ediciones Akal.

Sanabria, S. (2003). Rodrigo Gil de Hontañón’s new arithmetical structural rules at the parish church in Villamor de los Escuderos. En Huerta, S., De Herrera, J., SEdH, ETSAM, Benvenuto, A. E., COAM, Dragados, F. (eds.), Proceedings of the First International Congress on Construction History (pp. 1795-1799). Madrid.

Tosca, T. V. (1727). Tratado de la montea y cortes de cantería (2 a ed.). Madrid, España: Antonio Marín. Recuperado de http://www.udc. es/etsa/biblioteca/red/tratados2.htm

Vandelvira, A. (ca. 1591). Libro de traças de cortes de piedras. Recuperado de http://dicter. eusal.es/?obra $=$ VandelviraAlonso

Viollet-le-Duc, E. (1996). La construcción medieval. Madrid: Instituto Juan de Herrera. 
A Los artículos postulados deben corresponder a las categorías universalmente aceptadas como producto de investigación, ser originales e inéditos y sus contenidos responder a criterios de precisión, claridad y brevedad.

Como punto de referencia se pueden tomar las tipologías y definiciones del Índice Bibliográfico Nacional, Publindex, para los artículos tipo 1, 2 y 3 que se describen la continuación:

1) Artículo de investigación científica y tecnológica: documento que presenta, de manera detallada, los resultados originales de proyectos terminados de investigación. La estructura generalmente utilizada contiene cuatro apartes importantes: introducción, metodología, resultados y conclusiones.

2) Artículo de reflexión: documento que presenta resultados de investigación terminada desde una perspectiva analítica, interpretativa o crítica del autor, sobre un tema específico, recurriendo fuentes originales.

3) Artículo de revisión: documento resultado de una investigación terminada donde se analizan, sistematizan e integran los resultados de investigaciones publicadas o no publicadas, sobre un campo en ciencia o tecnología, con el fin de dar cuenta de los avances y las tendencias de desarrollo. Se caracteriza por presentar una cuidadosa revisión bibliográfica de por lo menos 50 referencias.

También se pueden presentar otro tipo de documentos diferentes a los anteriormente descritos como pueden ser: artículo corto, reporte de caso, revisión de tema, documento resultado de la revisión crítica de la literatura sobre un tema en particular, cartas al editor, traducción, documento de reflexión no derivado de investigación, reseña bibliográfica así como proyectos de arquitectura o urbanismo, entre otros.

(A) INSTRUCCIONES PARA POSTULAR ARTÍCULOS

Presentar el artículo mediante comunicación escrita dirigida al Editor de la Revista de Arquitectura en soporte digital y una copia impresa (si es local), adjuntando hoja de vida del autor (diligenciar el formato RevArq FP01 Hoja de Vida*). En la comunicación escrita el autor debe expresar, que conoce y acepta la política editorial de la Revista de Arquitectura, que el artículo no está postulado para publicación simultáneamente en otras revistas u órganos editoriales y que cede todos los derechos de reproducción y distribución del artículo (RevArq FP05 Carta de originalidad*).

Los artículos deben tener en cuenta las siguientes recomendaciones:

- En la primera página del documento se debe incluir

TíTULO: en español e inglés y no exceder 15 palabras.

SUBTíTULO: opcional, complementa el título o indica las principales subdivisiones del texto.

DATOS DEL AUTOR O AUTORES: nombres y apellidos completos, filiación institucional. Como nota al pie: formación académica, experiencia profesional e investigativa, publicaciones representativas y correo electrónico o dirección postal. El orden de los autores debe guardar relación con el aporte que cada uno hizo al trabajo.

DESCRIPCIÓN DEL PROYECTO DE INVESTIGACIÓN: en la introducción describir brevemente el marco investigativo del cual es producto el artículo y diligenciar el formato (RevArq FP02 Info Proyectos de Investigación*).

RESUMEN: debe ser analítico, se redacta en un solo párrafo, da cuenta del tema, el objetivo, los puntos centrales y las conclusiones, no debe exceder las 150 palabras y se presenta español e inglés (Abstract).

PALABRAS CLAVE: cinco palabras o grupo de palabras, ordenadas alfabéticamente y que no se encuentren en el título o subtítulo, deben presentarse español e inglés (Key words), estas sirven para clasificar temáticamente al artículo. Se recomienda emplear principalmente palabras definidas en el tesauro de la Unesco http:// databases.unesco.org/thessp/ o en el tesauro de Arte \& Arquitectura@ www.aatespanol.cl

- La segunda página y siguientes deben tener en cuenta estas recomendaciones:
El cuerpo del artículo generalmente se divide en: Introducción, Metodología, Desarrollo, Resultados y Discusión, y finalmente Conclusiones, luego se presentan las Referencias bibliográficas, Tablas, Leyendas de las Figuras y Anexos.

TEXTO: las páginas deben venir numeradas, a interlineado doble en letra Arial de 12 puntos, la extensión de los artículos debe estar alrededor de 5.000 palabras (20 páginas, incluyendo gráficos, tablas, etc.) y se debe seguir el estilo vigente y recomendado en el Manual para Publicación de la Asociación Americana de Psicología (APA). (Para mayor información http://www. apastyle.org/).

CITAS Y NOTAS AL PIE: las notas aclaratorias o notas al pie no deben exceder más de cinco líneas o 40 palabras, de lo contrario estas deben ser incorporadas al texto general. Cuando se realicen citas estas pueden ser cortas (con menos de 40 palabras), se incorporan al texto y pueden ser: textuales (se encierran entre dobles comillas), parafraseo o resumen (se escriben en sus propias palabras dentro del texto); cita textual extensa (mayor de 40 palabras) debe ser dispuesta en un renglón y un bloque independiente con sangrías y omitiendo las comillas, no olvidar en ningún caso la referencia del autor (Apellido, año, p. 00).

REFERENCIAS: como modelo para la construcción de referencias, se emplea el siguiente:

\section{Libro}

Autor -Apellidos-, A.A. -Nombres- (año de la publicación). Titulo de la obra (Edición). Ciudad: Editorial.

Capítulo de un libro

Autor, A.A., y Autor, B.B. (Año de la publicación). Título del capítulo. En A.A. Editor y B.B. Editor (eds.), Título del libro (páginas del capítulo). Ciudad: Editorial.

\section{Publicación seriada (Revista)}

Autor, A.A., Autor, B.B., y Autor, C.C. (Año de la publicación, incluya el mes y día de la publicación para publicaciones diarias, semanales o mensuales). Título del artículo. Título de la revista, diario, semanario, Volumen, (Número), páginas.

Leyes, decretos, resoluciones, etc.

Ley, decreto, resolución, etc., número (Año, incluya el mes y día de la publicación). Título de la ley, decreto, resolución, etc. Título de la publicación oficialmente. Ciudad, País. 


\section{DIRECCIÓN POSTAL}

Avenida Caracas N 46 - 72. Universidad Católica de Colombia. Bogotá D.C.- Colombia

Código postal: 111311

Centro de Investigaciones de la Facultad de Arquitectura (CIFAR). Sede

El Claustro. Bloque "L", 4 piso, Diag. 46모 No. 15b - 10.

Arq. César Andrés Eligio Triana

Teléfonos: (057-1) 3277300 - 3277333 Ext. 3109 ó 5146

\section{CORREO ELECTRÓNICO:}

revistadearquitectura@ucatolica.edu.co

cifar@ucatolica.edu.co

\section{PÁGINA WEB:}

www.ucatolica.edu.co Vínculo Publicaciones

http://portalweb.ucatolica.edu.co/easyWeb2/arquitectura/pages.

php/menu/319320363/id/2363/content/revista-de-arquitectura/
La Revista de Arquitectura está interesada en establecer canje con publicaciones académicas, profesionales o científicas, del área de Arquitectura y Urbanismo.

Para establecer canje por favor diligenciar y enviar el formato: RevArq FP20 Canjes.

\section{(A) PROCESO DE ARBITRAJE}

Artículo que se encuentra en una revista publicada en Internet

Autor, A.A. y Autor, B.B. (año). Título del artículo. Título de la revista, volumen (número, si se encuentra). Recuperado el día de mes de año, de URL.

SIGLAS: en el caso de emplear siglas en el texto, cuadros, gráficos y/o fotografías, se deben proporcionar las equivalencias completas de cada una de ellas la primera vez que se empleen y encerrarlas entre corchetes [ ]. En el caso de citar personajes reconocidos se deben colocar nombres y/o apellidos completos, nunca emplear abreviaturas.

GráfICOs: las tablas, los gráficos, las figuras, los diagramas, las ilustraciones y las fotografías deben contener el título o leyenda explicativa relacionada con el tema de investigación que no exceda las 15 palabras y la procedencia (autor $y / o$ fuente, año, p. 00). Se deben entregar en medio digital independiente del texto a una resolución mínima de 300 dpi (en cualquiera de los formatos descritos en la sección de fotografía), según la extensión del artículo se deben incluir de 5 a 10 gráficos y su posición dentro del texto.

El autor es el responsable de adquirir los derechos y/o las autorizaciones de reproducción a que haya lugar, para imágenes y/o gráficos tomados de otras fuentes.

FotografíA: pueden ser entregadas en original para ser digitalizadas, de lo contrario se deben digitalizar con una resolución igual o superior a 300 dpi para imágenes a color y 600 para escala de grises. Los formatos de las imágenes pueden ser TIFF, PSD o JPG.

Planimetría: se debe entregar la planimetría original en medio digital en lo posible en formato CAD y sus respectivos archivos de plumas o en PDF. De no ser posible se deben hacer impresiones en tamaño carta con las referencias de los espacios mediante numeración y lista adjunta. Deben poseer escala gráfica, escala numérica, norte, coordenadas y localización. En lo posible no debe tener textos, achurados o tramas.

Para más detalles puede consultar el documento RevArq Parámetros para Autores Descripción en el portal web de la Revista de Arquitectura (www.ucatolica.edu.co).
El Comité Editorial de la Revista de Arquitectura es la instancia que decide la aceptación de los artículos postulados, el editor selecciona y clasifica solo los artículos que cumplan con los requisitos establecidos en las instrucciones para los autores:

Todos los artículos se someterán a un primer dictamen del Comité Editorial teniendo en cuenta:

- Afinidad temática y relevancia del tema.

- Respaldo investigativo.

Después de la preselección se asignan pares evaluadores externos especializados, y se empleará método doble ciego y el formato (RevArq FP10 Evaluación de artículos calidad); del proceso de arbitraje se emitirá alguno de estos conceptos que serán reportados al autor:

- Aceptar el artículo tal como fue entregado.

- Aceptar el artículo con algunas modificaciones: se podrá sugerir la forma más adecuada para una nueva presentación, para lo cual el autor puede o no aceptar las observaciones, de ser así cuenta con quince días hábiles para realizar los ajustes pertinentes.

- Rechazar el artículo: en este caso se entregará al autor un comunicado, evidenciando la razón de la negación de publicación.

El Comité Editorial se reserva el derecho de aceptar o no la publicación del material recibido. También se reserva el derecho de sugerir modificaciones de forma y de someterlo a corrección de estilo.

Cuando un artículo es aceptado para su publicación, los derechos de reproducción y divulgación son de la Universidad Católica de Colombia, lo cual se hará mediante la firma de cesión de derechos (RevArq FP03 Autorización reproducción artículo).

\section{NOTAS ACLARATORIAS:}

Aunque la recepción del material se notificará de inmediato por correo electrónico, los procesos de evaluación, arbitraje, edición y publicación pueden tener un plazo máximo de doce meses.

El editor de la Revista de Arquitectura es el encargado de establecer contacto entre los autores, árbitros, evaluadores y correctores, ya que estos procesos se realizan de manera anónima.

Aunque un artículo sea aceptado podrá quedar aplazado para ser publicado en una próxima edición.
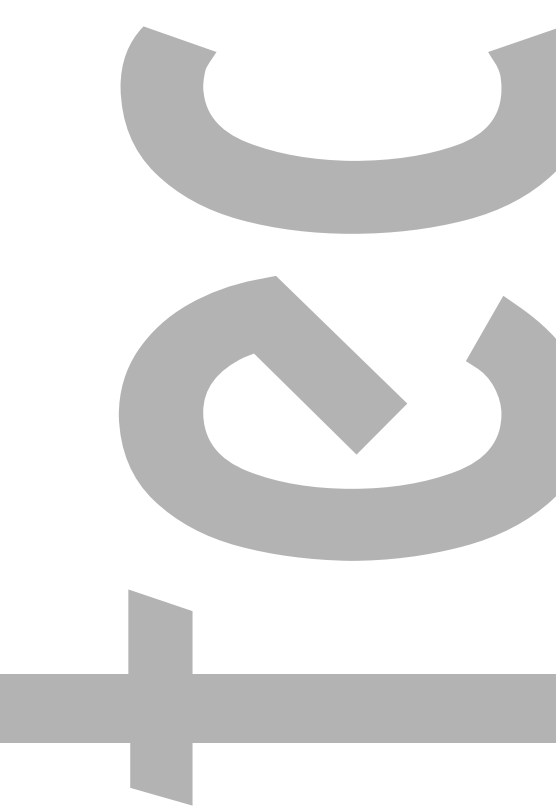

$>$
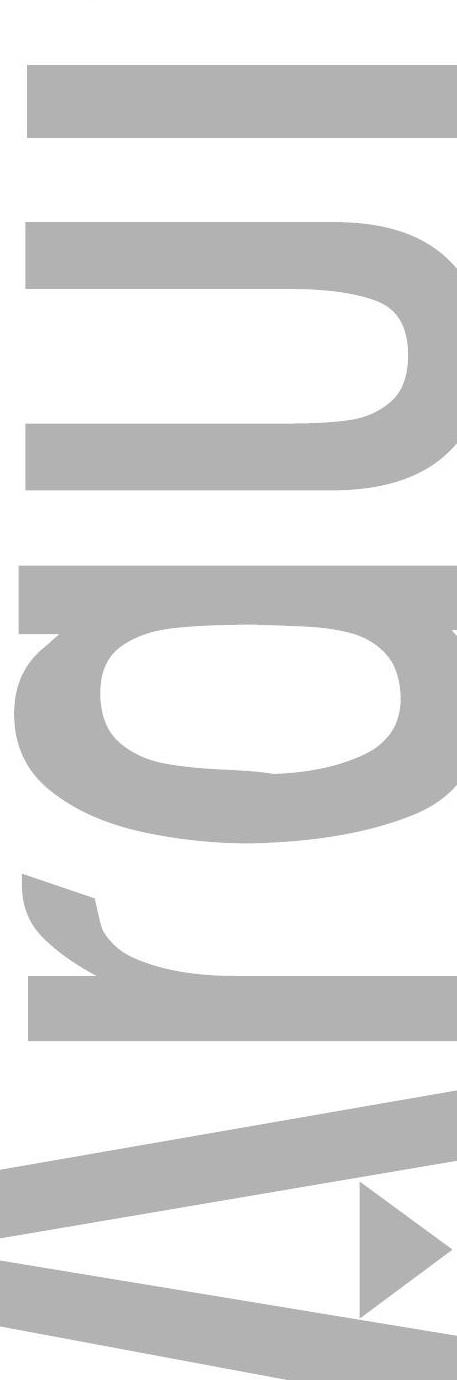
ARQUITECTURA PARTICIPATIVA:

广 LAS FORMAS DE LO ESENCIAL

$\begin{array}{ll}\dot{0} & \text { PARTICIPATIVE ARCHITECTURE: } \\ \dot{\alpha} & \text { FORMS OF THE ESSENTIAL }\end{array}$

WiLLIAM Garcia RAMIREZ

LA CIUDAD MODERNA, LITERALMENTE $\simeq$ HABLANDO

نं O CÓMO LEER LO QUE DICEN LOS ESCRITORES DE FICCIÓN SOBRE

¿ LOS ASENTAMIENTOS

THE MODERN CITY, LITERALLY SPEAKING

OR HOW TO READ WHAT FICTION WRITERS SAY ABOUT URBAN

MAURICIO MUÑOZ

UNA VENTANA PARA VER LA CIUDAD:

유 EL PARK WAY (1944 - 2000)

ن A WINDOW TO SEE THE CITY:

¿ THE PARK WAY (1944-2000)

José OrLando Jaimes Nieto

CARÁCTER, CARÁCTER PÚBLICO, CARACTERES \pm NACIONALES

ن VARIACIONES, PERSISTENCIAS E INTERPRETACIONES EN TORNO A

¿ LA EDILICIA PÚBLICA

CHARACTER, PUBLIC CHARACTER, NATIONAL CHARACTERS

VARIATIONS, PERSISTENCES AND INTERPRETATIONS AROUND THE PUBLIC EDILICIA

DANIELA ALEJANDRA CATTANEO

UN ACERCAMIENTO AL ESPACIO

- ARQUITECTÓNICO

ن AN APPROACH TO THE ARCHITECTURAL SPACE

$\llbracket$ Francisco JaVIER FUENTES Farias

PROPUESTA DE DISEÑO PARA UN TEATRO DE

m I500 ESPECTADORES

i. UNA MIRADA DESDE LOS ORÍGENES DE ESTA TIPOLOGÍA

¿ 2 ARQUITECTÓNICA

DESIGN PROPOSAL FOR A THEATER OF I 500 SPECTATORS

A LOOK FROM THE ORIGINS OF THIS ARCHITECTURAL TYPOLOGY

NORA Alvariño TAPIA

ERnesto FeLIPE SÁNCHEZ

GRANDES IDEAS DEL MUNDO: UNA REALIDAD CONCRETA

jo Tensiones en la Vivienda unifamillar moderna, Osorno, Chile

a GREAT IDEAS IN THE WORLD: A REALITY.

TENSIONS IN THE MOdern SINGLE FAMILY HOUSES, OSORNo, CHILE

Hugo Eduardo Weibel Fernandez

ESTUDIO Y GESTIÓN DE ESTÁNDARES MÍNIMOS

乞n DE FLEXIBILIDAD EN LA VIVIENDA SOCIAL EN

i BOGOTÁ

¿ STUDY OF MINIMUM STANDARDS OF FLEXIBILITY FOR SOCIAL HOUSING IN BOGOTÁ

Rolando Arturo Cubillos GONZALEZ

ESTRATEGIA DIDÁCTICA PARA EL APRENDIZAJE DE - LA HISTORIA Y LA TEORÍA DE LA ARQUITECTURA

نं DIDACTIC STRATEGY FOR THE LEARNING OF THE HISTORY AND THE THEORY OF \& THE ARCHITECTURE

\section{LO MISMO MUY DE OTRA MANERA}

SOBRE LA RELACIÓN ENTRE PROYECTO Y ANÁLIISIS EN EL

(j) APRENDIZAJE DE LA COMPOSICIÓN ARQUITECTÓNICA

THE SAME IN A VERY DIFFERENT WAY

ON THE RELATIONSHIP BETWEEN PROJECT AND ANALYSIS IN ARCHITECTURAL COMPOSITION LEARNING
TIPO, ANÁLISIS Y PROYECTO

a TYPE, ANALYYIS AND PROJECT

¿ें

TRAZO DE LAS BÓVEDAS DE NERVADURAS ○ MEXICANAS DEL SIGLO XVI

Tracing of RibBed VAults of THe I6TH Century In MeXICO

这

CONCEPTUALIZACIÓN DE UN MODELO DE ○ INTERVENCIÓN URBANA SOSTENIBLE

- Ecobarrios en el CONTEXTO LATINOAMERICANO DE RECIENTE

¿

CONCEPTUALIZING A SUSTAINABLE URBAN INTERVENTION MODEL

ECO-NEIGHBORHOODS IN THE RECENTLY INDUSTRIALIZED LATIN-AMERICAN

CONTEXT

AdRIANA PATRICIA LÓPEZ VALENCIA

OSWALDO LÓPEZ BERNAL

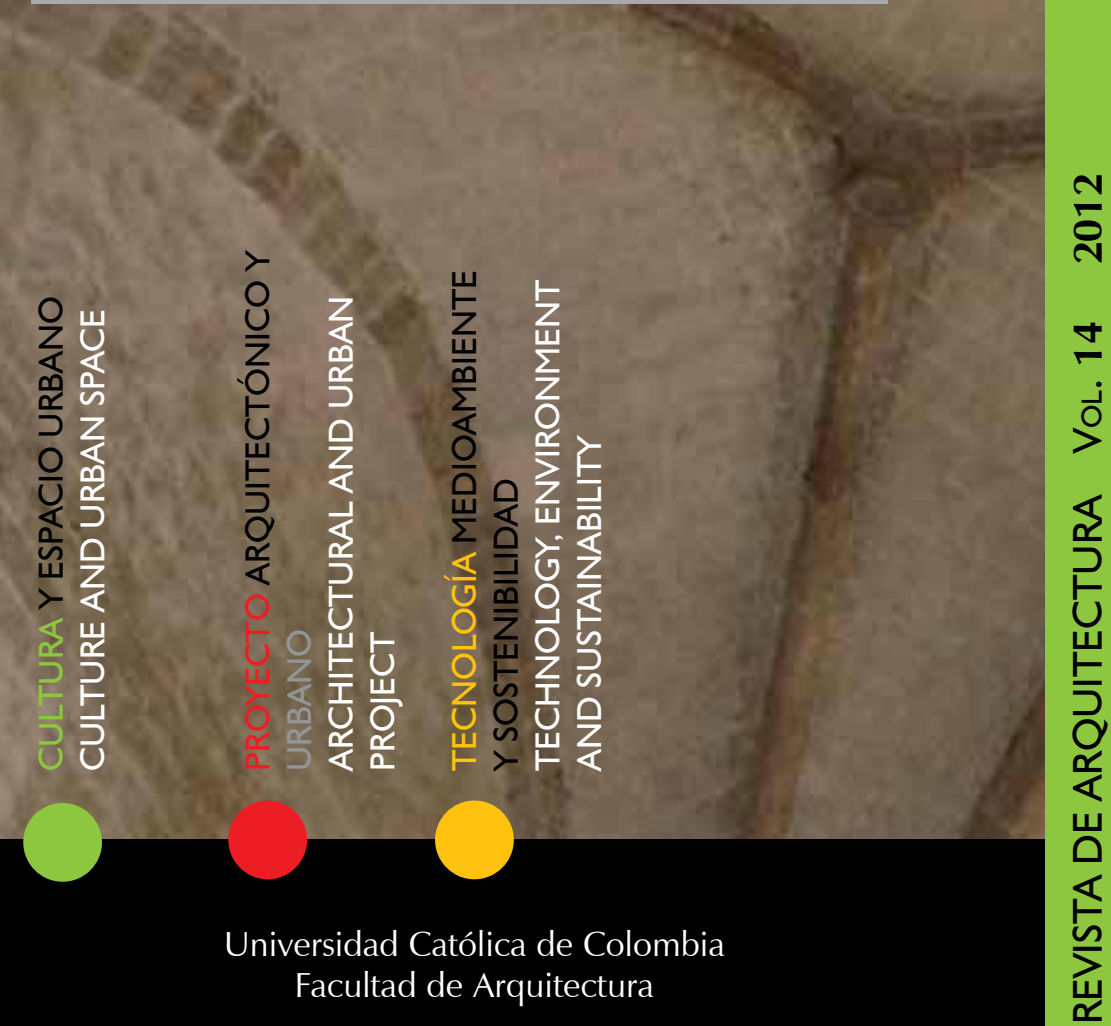

Reacreditación de alta calidad otorgada al Programa

de Arquitectura por el

Ministerio de Educación

Nacional. Resolución 3339 de abril 25 de 2011

Revalidación internacional del Programa de

Arquitectura otorgada por el Royal Institute of British Architects, RIBA

\section{CNA}

RIBA

La Revista de Arquitectura es arbitrada e indexada y está presente en:

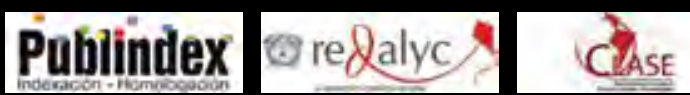

o Dialnet latindex

GiRLA 른 EBSCO

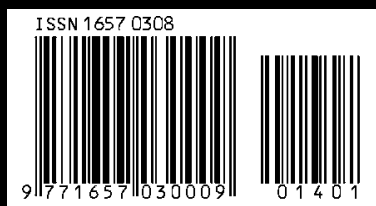

